\title{
Sensitivity of WRF cloud microphysics to simulations of a severe thunderstorm event over Southeast India
}

\author{
M. Rajeevan ${ }^{1}$, A. Kesarkar ${ }^{1}$, S. B. Thampi ${ }^{2}$, T. N. Rao $^{1}$, B. Radhakrishna ${ }^{1}$, and M. Rajasekhar ${ }^{3}$ \\ ${ }^{1}$ National Atmospheric Research Laboratory, Gadanki, 517 112, India \\ ${ }^{2}$ Doppler Weather Radar Division, India Meteorological Department, Chennai, India \\ ${ }^{3}$ SHAR Center, ISRO, Sriharikota, India
}

Received: 15 July 2009 - Revised: 16 February 2010 - Accepted: 16 February 2010 - Published: 19 February 2010

\begin{abstract}
In the present study, we have used the Weather Research and Forecasting (WRF) model to simulate the features associated with a severe thunderstorm observed over Gadanki $\left(13.5^{\circ} \mathrm{N}, 79.2^{\circ} \mathrm{E}\right)$, over southeast India, on 21 May 2008 and examined its sensitivity to four different microphysical (MP) schemes (Thompson, Lin, WSM6 and Morrison). We have used the WRF model with three nested domains with the innermost domain of $2 \mathrm{~km}$ grid spacing with explicit convection. The model was integrated for $36 \mathrm{~h}$ with the GFS initial conditions of 00:00 UTC, 21 May 2008. For validating simulated features of the thunderstorm, we have considered the vertical wind measurements made by the Indian MST radar installed at Gadanki, reflectivity profiles by the Doppler Weather Radar at Chennai, and automatic weather station data at Gadanki.

There are major differences in the simulations of the thunderstorm among the MP schemes, in spite of using the same initial and boundary conditions and model configuration. First of all, all the four schemes simulated severe convection over Gadanki almost an hour before the observed storm. The DWR data suggested passage of two convective cores over Gadanki on 21 May, which was simulated by the model in all the four MP schemes. Comparatively, the Thompson scheme simulated the observed features of the updraft/downdraft cores reasonably well. However, all the four schemes underestimated strength and vertical extend of the updraft cores. The MP schemes also showed problems in simulating the downdrafts associated with the storm. While the Thompson scheme simulated surface rainfall distribution closer to observations, the other three schemes overestimated observed rainfall. However, all the four MP schemes simulated the surface wind variations associated with the thunderstorm reasonably well. The model simulated reflectivity
\end{abstract}

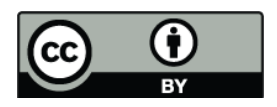

Correspondence to: M. Rajeevan (rajeevan@narl.gov.in) profiles were consistent with the observed reflectivity profile, showing two convective cores. These features are consistent with the simulated condensate profiles, which peaked around 5-6 km. As the results are dependent on initial conditions, in simulations with different initial conditions, different schemes may become closer to observations. The present study suggests not only large sensitivity but also variability of the microphysical schemes in the simulations of the thunderstorm. The study also emphasizes the need for a comprehensive observational campaign using multi-observational platforms to improve the parameterization of the cloud microphysics and land surface processes over the Indian region.

Keywords. Meteorology and atmospheric dynamics (Mesoscale meteorology)

\section{Introduction}

Mesoscale convective systems (MCS), the largest of the convective systems account for a large proportion of precipitation in both the Tropics and mid-latitudes. Slow moving MCSs are a major cause of flooding and these systems often contain hail and strong winds. A broad descriptive definition of an MCS is an ensemble of thunderstorms that produces a contiguous precipitation area of around $100 \mathrm{~km}$ or more in at least one direction (Houze, 2004). However, the dynamics of an MCS are often more complex than those of individual cumulonimbus clouds or lines of cumulonimbus (Houze, 1993). MCSs often contain a large region of stratiform precipitation and mesoscale circulations and they are important link between atmospheric convection and the large-scale atmospheric circulation (Houze, 2004).

Prediction of MCSs and severe thunderstorms are particularly important to commercial and general aviation, space vehicle launch operations and power utilities, among many

Published by Copernicus Publications on behalf of the European Geosciences Union. 
other sectors. The techniques for predicting thunderstorms can be classified into two groups (Wilson et al., 1998). One method is a historical treatment of thunderstorm extrapolation techniques, first assuming no change in motion, size and intensity and second allowing for changes in size and intensity based on past trends. The second method is explicit prediction using high resolution numerical weather prediction models. Prediction of thunderstorms is one of the most difficult tasks in weather prediction, due to rather smaller spatial and temporal scales and the inherent non-linearity of their dynamics and physics. The inadequate treatment of sub-grid convection is widely believed to be a major impediment for improving the poor performance of Numerical Weather Prediction (NWP) models in precipitation forecasting (Liu and Moncrieff, 2007). The improvement in the existing convective parameterizations is however rather slow. Since, the computing power has now advanced, the use of highresolution explicit (convection permitting) numerical models is recommended. With the growing computing power, it is anticipated that the horizontal grid space in operational NWP models, perhaps even global models will be a few kilometers within a decade (Liu and Moncrieff, 2007). The high-resolution 3-6 km grid spacing simulations of precipitation using convection allowing configuration showed good promise (Done et al., 2004; Liu et al., 2006; Kain et al., 2006, 2008; Moncrieff and Liu, 2006; Trier et al., 2006; Lean et al., 2008). There are several reasons for better performance by the high-resolution models. The increased resolution is expected to enable the model to represent mesoscale features that would otherwise not be resolved and to represent convection rather explicitly rather than by a convection parameterization. There are number of studies (Weisman et al., 1997; Speer and Leslie, 2002; Done et al., 2004) suggesting improved representation of thunderstorms and squall lines as the grid length is reduced toward $1 \mathrm{~km}$. The study by Done et al. (2004) compared the forecast performance of two forecasts configurations. One configuration used a $10-\mathrm{km}$ grid spacing with parameterized convection. In the other configuration, much larger resolution $(4 \mathrm{~km})$ with explicit convection was used. Their analysis showed that the convection explicit forecasts with a 4-km grid spacing more often predict identifiable MCSs. Further, such predictions more accurately predict the number of MCSs daily and type of organization. Kain et al. (2008) used two configurations of the WRF model to produce 30-h forecasts, 5 days a week and for a total of 7 weeks. These configurations used the same physical parameterizations and same initial and boundary conditions, differing only the spatial resolution. The results showed that in general, the $2-\mathrm{km}$ forecasts provide more detailed presentations of convective activity, but there appears to be little forecast skill on the scales where the added details emerge. However, these studies are for the mid-latitude weather systems, where the frontal systems can dominate the model performance. However, the role of grid spacing on model performance cannot be transformed to Indian monsoon region.
Cloud microphysical processes play an important role through direct influences on the cold pool strength (due to rainfall evaporation) and latent heating (due to condensation). Therefore, microphysical parameterizations could be a principal source of uncertainty in convection allowing high resolution numerical weather prediction models. It is important to quantify the uncertainty associated with the cloud microphysics parameterization - a salient concern in convection permitting models. It is also important to assess whether increasingly sophisticated cloud microphysics gives consistently better results. Therefore, assessing the cloud microphysical schemes is not only of practical significance but also helpful for guiding the future improvement of cloud microphysics parameterizations.

The sensitivity of cloud microphysics in predicting convective storms and precipitation has been addressed by many researchers (McCumber, 1991; Gilmore et al., 2004; Reisner et al., 1998; Liu and Moncrieff, 2007). Liu and Moncrieff (2007) evaluated the sensitivity of explicit simulations of coherent rainfall patterns to several bulk microphysical schemes using multi-day cloud-system-resolving simulations at $3 \mathrm{~km}$ grid spacing. They compared four microphysical parameterization schemes. They found that upperlevel condensate and cloudiness, upper-level radiative cooling/heating and rainfall spectrum are the most sensitive, whereas the domain-mean rainfall rate and areal coverage display moderate sensitivity. Overall, three mixed phase schemes outperform the simple ice scheme but a general conclusion about the degree of sophistication in the microphysics treatment and the performance is not achievable.

In India, studies related to modeling of clouds and thunderstorms are scarce. Recently, Litta and Mohanty (2008) simulated features of a severe thunderstorm event observed over north-east India (Kolkata) using WRF (NMM) model using field experiment data and concluded that high-resolution models have the potential to provide unique and valuable information for severe thunderstorm forecasters. Mukhopadhayay et al. (2005) analyzed the impact of assimilation of surface meteorological observations on monsoon weather systems including thunderstorms over the Indian region using RAMS model.

At the National Atmospheric Research Laboratory (NARL), Gadanki, $\left(13.5^{\circ} \mathrm{N}, 79.2^{\circ} \mathrm{E}\right)$ India, an experimental campaign was recently initiated to Study the Atmospheric Forcing and Response (SAFAR) to address the responses of the earth's atmosphere to both natural and anthropogenic forcings using different observational platforms and models. As a prelude to the main program a pilot campaign was conducted at Gadanki during 2008 using collocated observations from the MST radar, Rayleigh lidar, GPS sonde, automated weather stations and instruments measuring aerosol, radiation and precipitation and supporting satellite data.

As a part of the SAFAR campaign, we have simulated a severe thunderstorm event occurred over Gadanki on 21 May 2008 and examined the sensitivity of the simulation to 


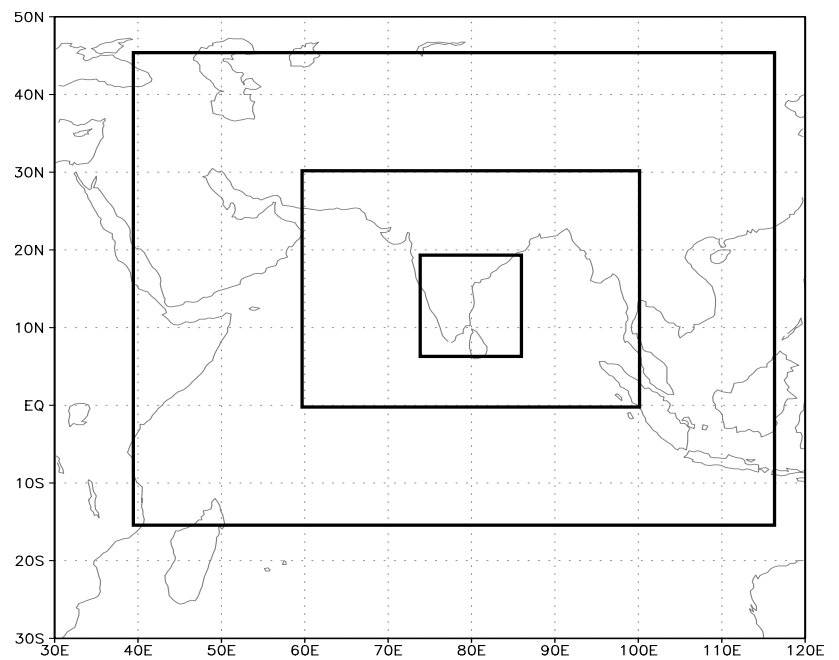

Fig. 1a. Nested model domains used for the simulation of the thunderstorm. Domain resolution is $32 \mathrm{~km}, 8 \mathrm{~km}$ and $2 \mathrm{~km}$, respectively.

different cloud microphysical schemes. The primary objectives of this study are to examine whether the high resolution WRF model is capable of simulating the observed features of the thunderstorm and the sensitivity of simulation to different microphysics. The simulations are done with the grid spacing of $2 \mathrm{~km}$ resolution with no cumulus parameterization but using explicit convection. In particular, we have examined the updrafts and downdrafts associated with the thunderstorm, spatial distribution of rainfall and surface wind and the vertical profiles of reflectivity and hydrometeors. Available data from the Indian Mesosphere-Stratosphere-Troposphere (MST) radar, Doppler Weather Radar (DWR) data and other observational platforms at NARL were used to verify the simulated features of the convective event.

In Sect. 2, data and methods are described. The Sect. 3 deals with the main results of the model simulations and the conclusions are drawn in Sect. 4.

\section{Data and methodology}

In the present study, we have used the Weather Research and Forecasting (WRF) model version 3.0 for the simulations of the MCS event and features associated with the thunderstorm observed over Gadanki on 21 May 2008. We have used the model with Advanced Research WRF (ARW) dynamical core. For model simulations, we have considered a configuration with three nested domains of $32 \mathrm{~km}, 8 \mathrm{~km}$ and $2 \mathrm{~km}$ grid spacing. The configurations used for model simulations are shown in Fig. 1a. For better simulation of the thunderstorm event, inner most domain with $1 \mathrm{~km}$ resolution will be ideally required. However, due to the limited computing resources, we have considered the innermost domain with $2 \mathrm{~km}$ resolution. The model used 38 vertical levels with the top of
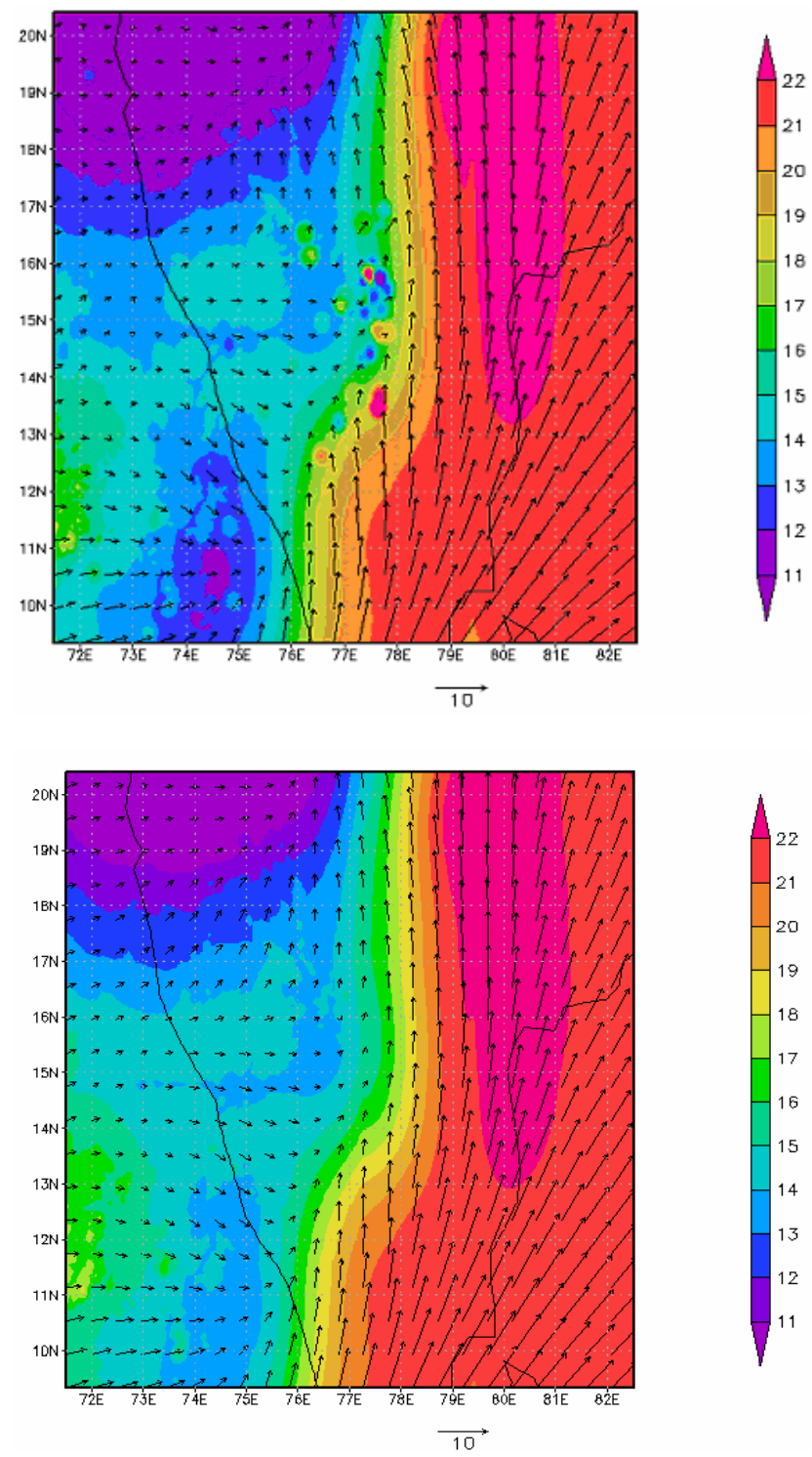

Fig. 1b. Spatial distribution of surface winds and specific humidity $\left(\mathrm{g} \mathrm{kg}^{-1}\right)$ at 00:00 UTC, 21 May 2008 without data assimilation (top) and with data assimilation (below).

model at $10 \mathrm{hPa}$. The model was initialized with the GFS initial conditions of 0.5 degree resolution of 00:00 UTC of 21 May 2008. The model was integrated up to $24 \mathrm{~h}$ with every $3 \mathrm{~h}$ updates of the boundary conditions taken from the GFS analysis. In addition, all available observations at 00:00 UTC of 21 May from 230 Automatic weather stations (AWS) over south peninsula, MST radar profiles and GPS sonde profiles were also assimilated into the model using the observation nudging technique. The observations during the period 00:00-03:00 UTC are considered for the assimilation. Before assimilation, the duplicate observations are ignored. The quality and consistency checks are performed. The assimilation is done using the observation nudging method described 
Table 1. Details of the microphysical schemes considered in the study.

\begin{tabular}{llccc}
\hline Scheme & Reference & $\begin{array}{c}\text { Number of } \\
\text { variables }\end{array}$ & $\begin{array}{c}\text { Ice-phase } \\
\text { processes }\end{array}$ & $\begin{array}{c}\text { Mixed phase } \\
\text { processes }\end{array}$ \\
\hline WSM6 & Hong et al. (1994) & 6 & $\mathrm{Y}$ & $\mathrm{Y}$ \\
Purdue Lin & Chen and Sun (2002) & 6 & $\mathrm{Y}$ & $\mathrm{Y}$ \\
Thompson & Thompson et al. (2004) & 7 & $\mathrm{Y}$ & $\mathrm{Y}$ \\
Morrison & Morrison et al. (2009) & 10 & $\mathrm{Y}$ & $\mathrm{Y}$ \\
\hline
\end{tabular}

by Multi-quardratic Scheme. The Multi-quadric scheme uses hyperboloid radial basis functions to perform the objective analysis. If observations are not sufficient to evaluate multiquadratic function, the Cressman method is used for nudging these observations. The observation nudging is done with the existing option available in the WRF model. Figure $1 \mathrm{~b}$ shows the difference in the surface wind flow and specific humidity at 00:00 UTC of 21 May with and without data assimilation. There are changes in the surface specific humidity and wind circulation over south India due to assimilation of local meteorological data.

The Betts Miller Janjic (BMJ) Cumulus parameterization scheme was used in the first and second domains, while explicit convection was used in the cloud-resolving innermost domain ( $2 \mathrm{~km}$ grid spacing). Radiation is treated using the RRTM long-wave scheme, a spectral-band radiative transfer model using the correlated K-method (Mlawer et al., 1997) and the Dudhia (1989) shortwave scheme. For the land surface process, Noah LSM scheme was used.

Four microphysical schemes were considered to examine the sensitivity of the cloud microphysics in the simulation of convective updrafts. Microphysics in the model includes explicitly resolved water vapor, cloud and precipitation processes. The schemes considered are single moment six-class (WSM6) scheme (Hong et al., 2004), the Thompson Scheme (Thompson et al., 2004), the Purdue Lin Scheme (Chen and Sun, 2002) and the double moment Morrison Scheme (Morrison et al., 2009). A comparison of the microphysical schemes is given in Table 1.

The six-class WSM6 scheme extends the WSM5 scheme to include graupel and its associated processes. Some of the graupel-related terms follow Lin et al. (1983) and its icephase behaviour is much different due to the changes of Hong et al. (2004). In the Purdue Lin scheme, six classes of hydrometeors (water vapour, cloud water, rain, cloud ice, snow and graupel) are considered. All parameterization production terms are based on Lin et al. (1983) and Rutledge and Hobbs (1984) with some modifications. The scheme is taken from the Purdue cloud model and the details can be found in Chen and Sun (2002). Thompson scheme is also a single moment scheme, but it incorporates a large number of improvements to both physical process and computer coding plus employs many techniques found in far more sophisti- cated spectral/bin schemes. The assumed snow size distribution depends on both ice water content and temperature and is represented as a sum of exponential and gamma distributions. Morrison scheme (Morrison et al., 2009) is however a double moment scheme and six species of water (vapour, cloud droplets, cloud ice, rain, snow and graupel/hail) are considered. Prognostic variables include number concentrations and mixing ratios of cloud ice, rain, snow and graupel/hail and mixing ratios of cloud droplets and water vapour (total 10 variables). The prediction of two moments (i.e., both number concentration and mixing ratio) allows for a more robust treatment of the particle size distributions, which are a key for calculating the microphysical process rates and cloud/precipitation evolution.

Since the storm data are not included in the initial conditions, low level convergence in these simulations takes some time to spin up from the large scale circulation and hence the models are not generally reliable for the first $6 \mathrm{~h}$ or so (Wilson et al., 1998). Therefore, we have considered only the results from 06:00 UTC of 21 May for further discussions.

Convective updrafts and downdrafts associated with the thunderstorm can be measured directly by the MST radar facility installed at NARL, Gadanki. Indian MST radar is a high power coherent pulsed Doppler radar operating at $53 \mathrm{MHz}$ located at Gadanki, It consists of 1024 crossed three elements Yagi antennas. It generates a radiation pattern with a main beam of $3^{\circ}$, gain of $36 \mathrm{~dB}$ and a side lobe level of $-20 \mathrm{~dB}$. It makes use of the Doppler Beam Swing (DBS) technique for measuring wind field. The DBS method for measuring the three components of the vector requires spectral measurements at a minimum of three non coplanar beam positions. More details of the MST Radar are given in Rao et al. (1995). Jagannadha Rao et al. (2003) and Rao et al. (2009) used the Indian MST radar data to characterize mean vertical velocities over Gadanki. Recently, Uma and Narayana Rao (2009) used the Indian MST radar measurements during the passage of 60 convective systems to study vertical velocity characteristics of tropical convection. They have found that variation of vertical velocity distribution with height is different for different convection categories like shallow, deep and decaying convection. Strong updrafts of the order of 15$20 \mathrm{~m} \mathrm{~s}^{-1}$ in the upper troposphere have been observed associated with the deep convective systems over Gadanki. 


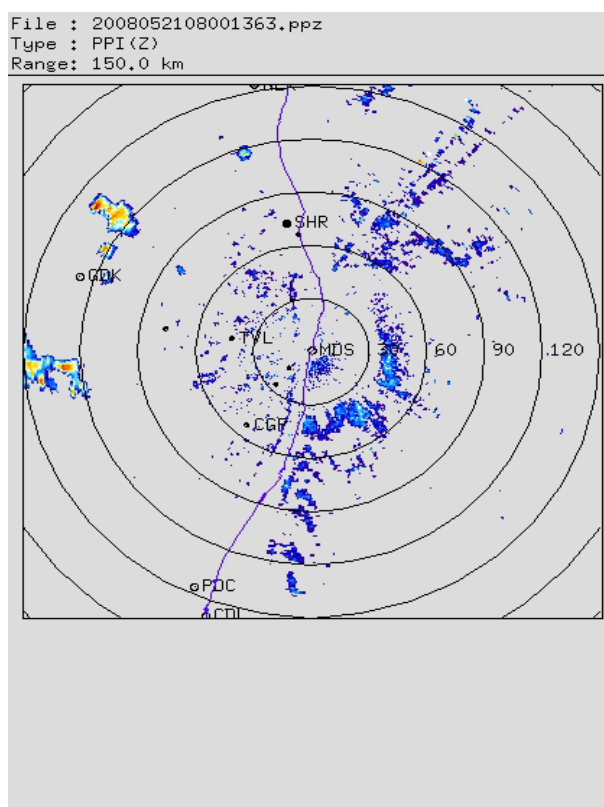

(a) $0800 \mathrm{UTC}$

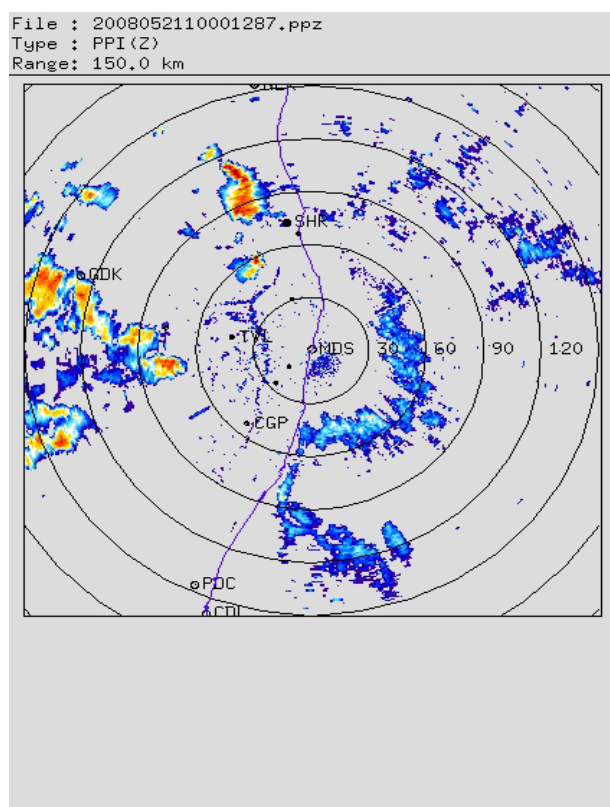

(c)1000 UTC
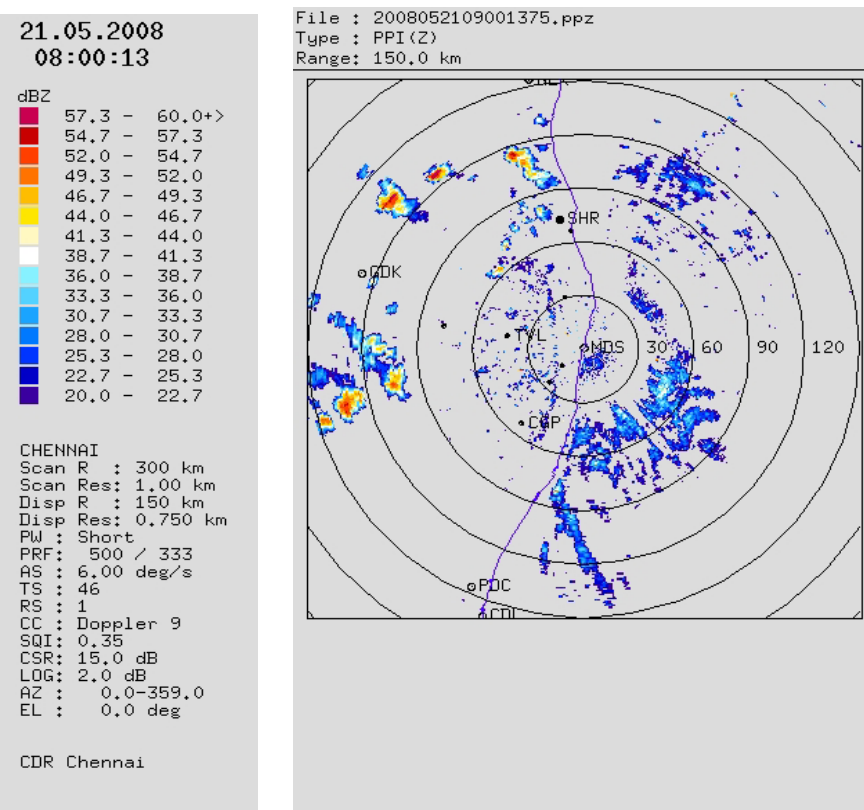

(b) 0900 UTC

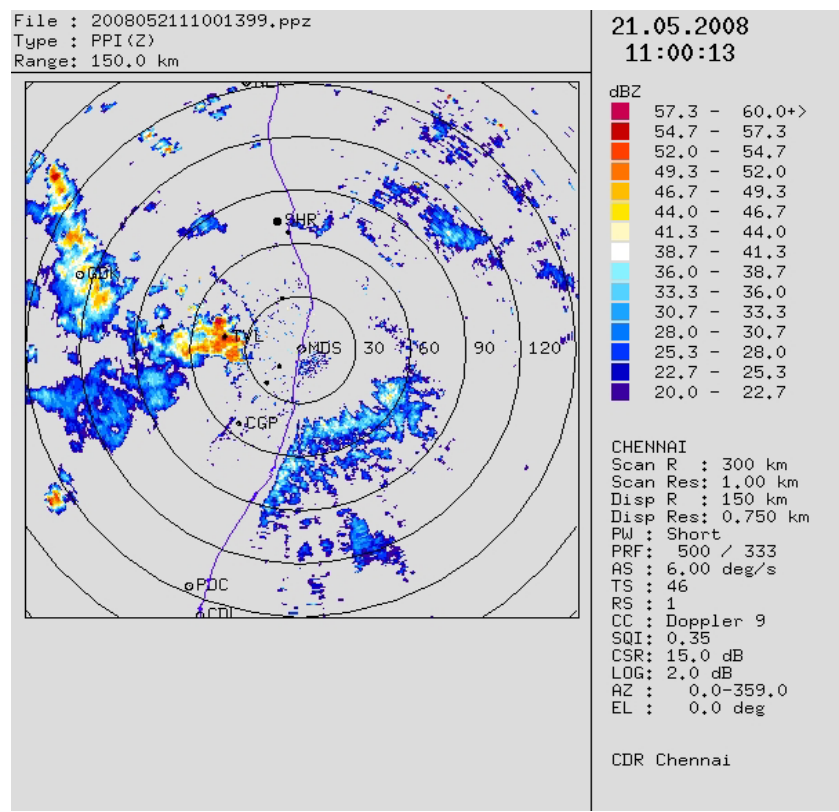

(d) 1100 UTC
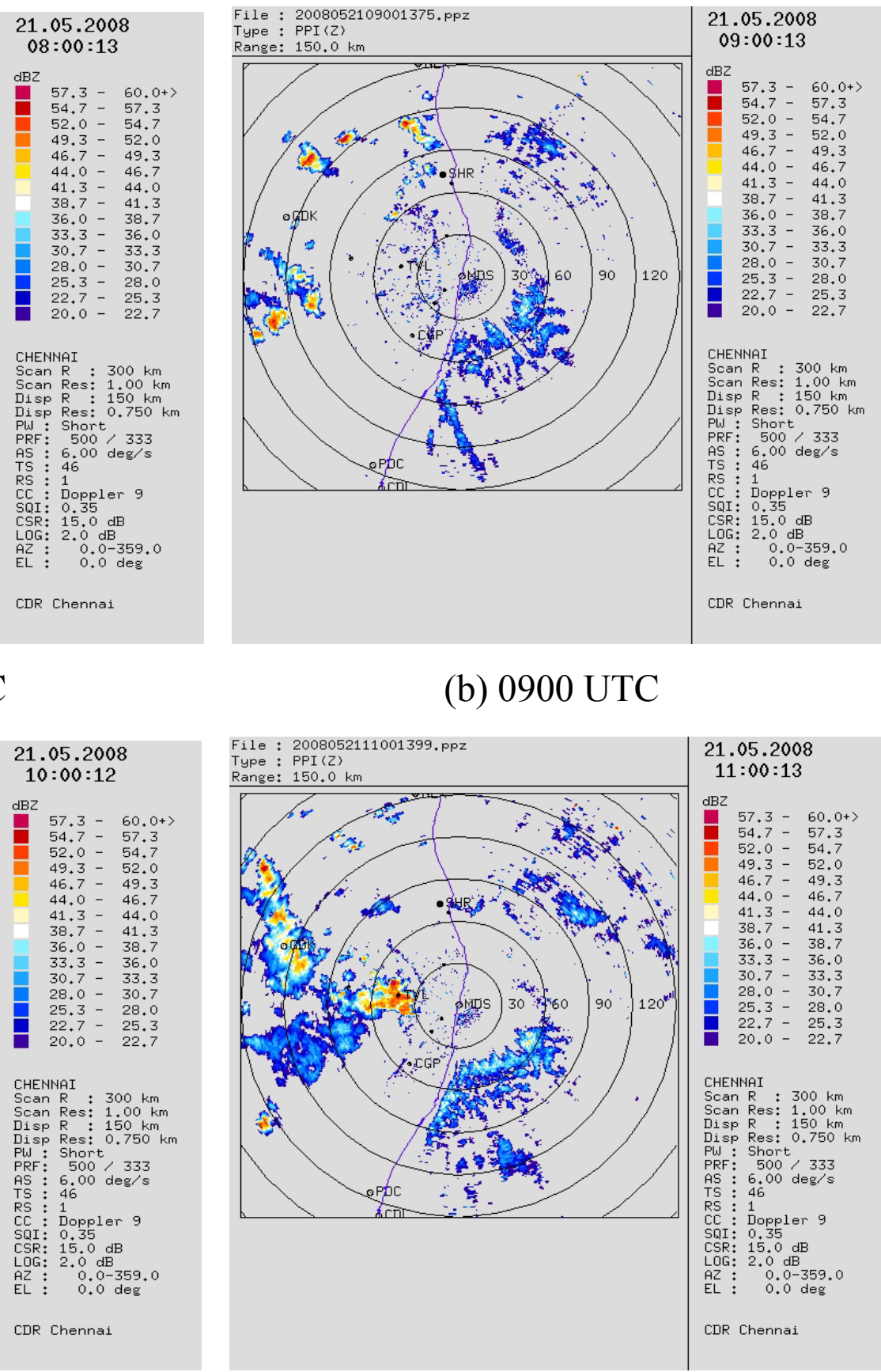

(d) $1100 \mathrm{UTC}$

Fig. 2. Spatial distribution of maximum reflectivity observed by the DWR at Chennai at (a) 08:00 UTC, (b) 09:00 UTC, (c) 10:00 UTC, and (d) 11:00 UTC.

The reflectivity profile data are the observations taken by the Doppler weather radar (DWR) installed at Chennai. For analyzing surface observed features of the thunderstorm over Gadanki, we have used the AWS observations recorded at Gadanki on 21 May 2008. For comparing simulated surface rainfall features, we have used the high resolution gridded rainfall data (Rajeevan and Bhate, 2009) prepared by the India Meteorological Department (IMD). This gridded data set at $0.5 \times 0.5$ degree Lat/Long resolution was prepared by interpolating more than 3000 rain-gauge data into regular grids. 

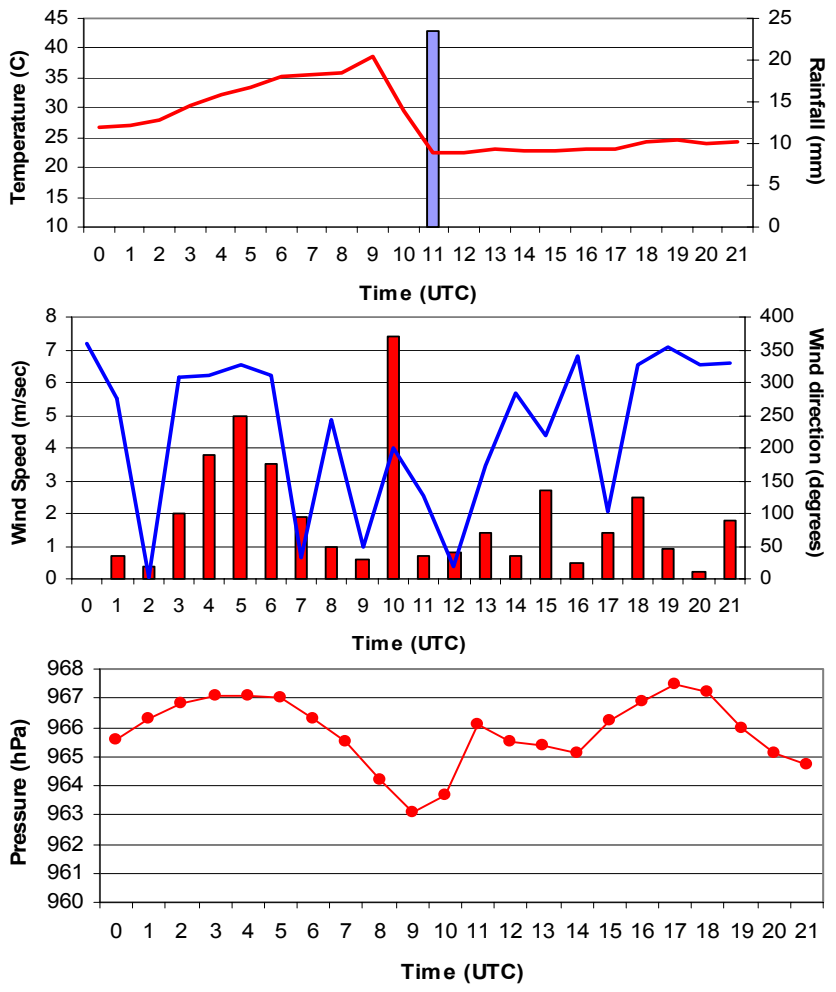

Fig. 3. Details of the thunderstorm observed over Gadanki on 21 May 2008. The top panel shows the variation of dry bulb temperature (continuous line) and rainfall in $\mathrm{mm}$ (vertical bar). The middle panel shows variation of wind direction (line) and wind speed (vertical bars). The bottom panel shows the variation of surface pressure on 21 May 2008.

There is good density of rain-gauges over south-east India for interpolating rainfall into regular grids. More details of this data set are available in Rajeevan and Bhate (2009).

\section{Results and discussions}

\subsection{Details of the thunderstorm}

The convective event occurred in the afternoon of 21 May along the line of convergence observed over south peninsula in the lower troposphere (Fig. 1b). Figure 2 shows the spatial distribution of maximum reflectivity recorded by the Doppler weather Radar (DWR) at Chennai, which shows the genesis, intensification and propagation of the convective event. The genesis of the event was observed over southwest of Gadanki around 07:00 UTC on 21 May and the line of convective clouds propagated northeastwards and started dissipating after around 12:00 UTC. Maximum reflectivity exceeding $40 \mathrm{dbz}$ was observed over Gadanki during the passage of the convective event. In association with this convective event, a severe thunderstorm was observed over Gadanki around 10:00 UTC. The main features of the thunderstorm observed over Gadanki on 21 May 2008 are given in Fig. 3. It shows the variation of dry bulb temperature, rainfall, wind speed and direction and surface pressure recorded by the Automatic Weather Station (AWS) installed at Gadanki. The temperature record shows sudden cooling associated with the passage of cold front ahead of the thunderstorm. The cooling was very rapid, about $15^{\circ} \mathrm{C}$ in just two hours. Rainfall of $23 \mathrm{~mm}$ was reported at around 11:00 UTC. Associated with the passage of the thunderstorm, there were abrupt changes in the wind direction and speed, wind speed increased up to $7.5 \mathrm{~m} \mathrm{~s}^{-1}$ and wind direction changed from northwesterly to southeasterly winds. Surface pressure also showed a small rise around 11:00 UTC associated with the passage of the meso-high of the thunderstorm. All these observed variations were consistent with such variations of meteorological parameters associated with a thunderstorm.

Spatial distribution of accumulated 24-h rainfall observed as on 22 May 2008 is shown in Fig. 4a. Accumulated rainfall is estimated from rain-gauge stations archived at the India Meteorological Department (IMD) (Rajeevan and Bhate, 2009). The distribution suggests rainfall of the order of $35 \mathrm{~mm}$ between $13^{\circ}-16^{\circ} \mathrm{N}$, east of $77.5^{\circ} \mathrm{E}$, associated with the convective event. The observed vertical profile of reflectivity over Gadanki measured by the DWR at Chennai is shown in Fig. 4b. It shows a sharp rise in reflectivity up to around $10 \mathrm{~km}$ as the thunderstorm passed over Gadanki. It shows passage of two convective cores, one just after 10:00 UTC and another after 11:00 UTC. The second convective core persisted over Gadanki for a longer time. Reflectivity was found to be maximum $(>40 \mathrm{dbz})$ in the lower troposphere below $5 \mathrm{~km}$. Reflectivity values exceeding $30 \mathrm{dbz}$ was observed extending up to $10 \mathrm{~km}$. Reflectivity values decreased just after 12:00 UTC, as the storm moved away.

Convective updraft speeds determine the vertical transport of convective condensate and the detrainment into anvils, whose microphysical and radiative properties are important to climate feedbacks. They also regulate interactions among supercooled liquid water, graupel and ice above the freezing level and control the occurrence of lightning, which is a leading cause of weather-related fatalities and property damage. Many previous studies have used convective updraft speeds to define the intensity of convection, with greater convective updraft speeds indicating more intense storms that lofts more ice into anvils and produce more lightning (Zipser et al., 2006). Statistics of updrafts will be useful to improve the cumulus parameterization schemes used in numerical weather prediction and climate models. For example, Xu and Randall (2001) made a detailed analysis of updraft and downdraft statistics of simulated tropical oceanic and midlatitude continental cumulus convection. Wu et al. (2009) using a WRF model simulated convective updraft properties during Tropical Warm Pool-International Cloud Experiment (TWP-ICE) near Darwin, Australia. They found that the model was able to simulate the changes in the updraft properties between 


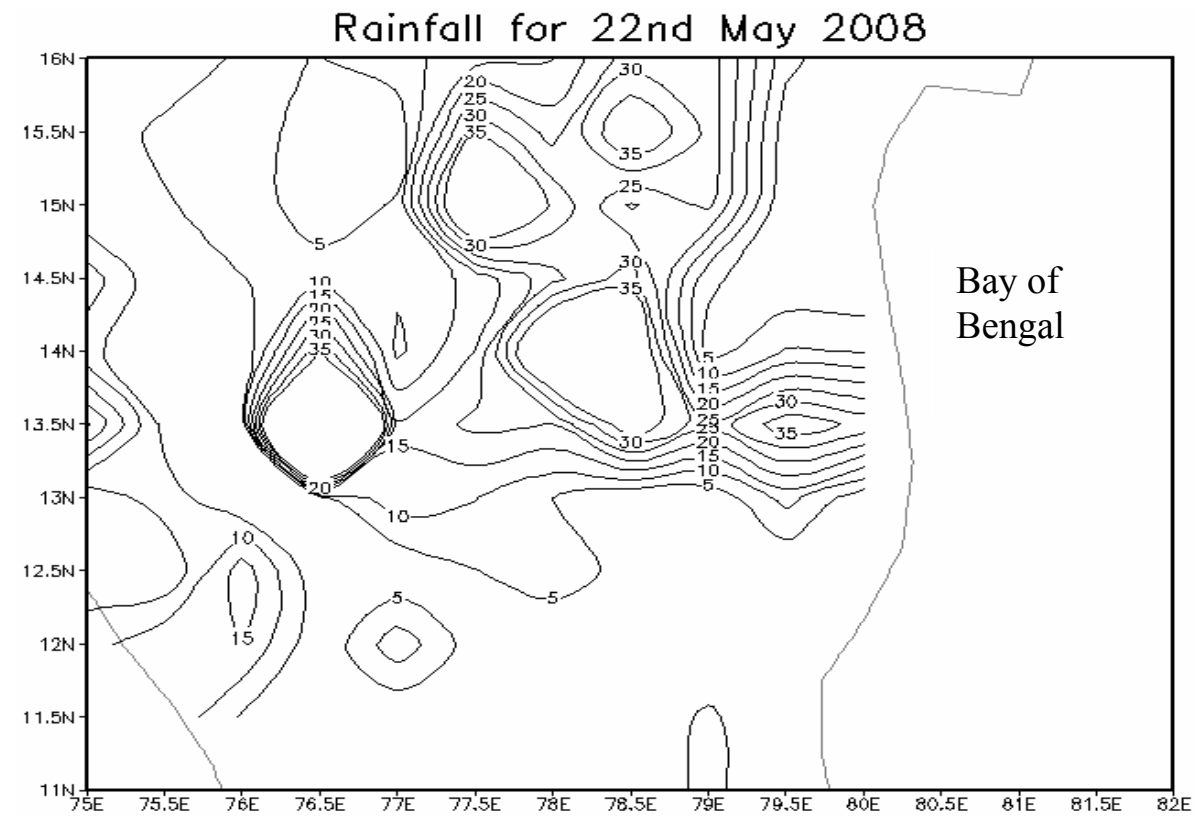

Fig. 4a. Observed $24 \mathrm{~h}$ accumulated rainfall (mm) ending 00:00 UTC of 22 May 2008 from IMD rain-gauge observations.

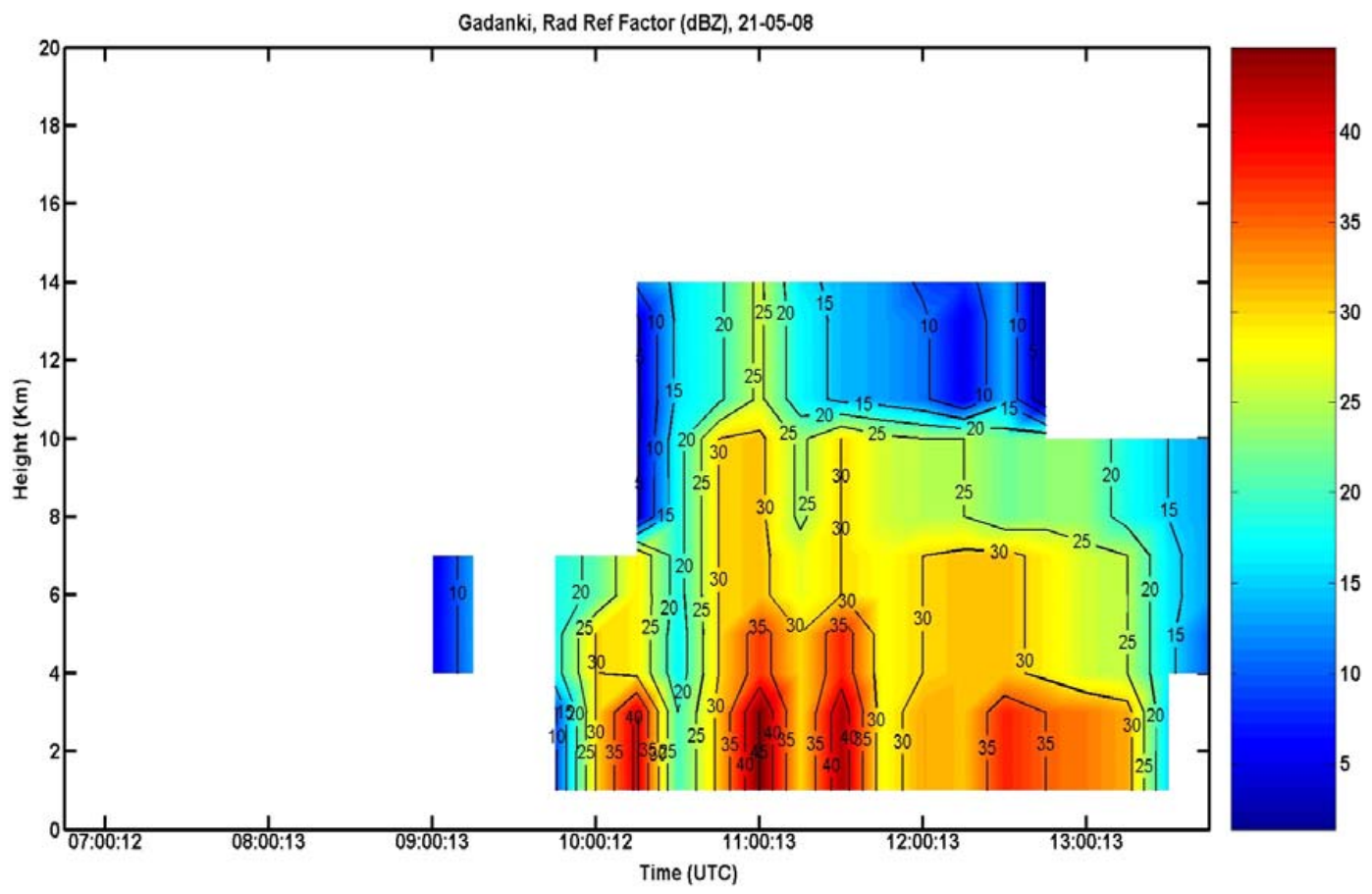

Fig. 4b. Vertical profile of reflectivity (dbz) at Gadanki on 21 May 2008 measured by the Doppler Weather Radar (DWR) at Chennai.

active, weak and suppressed monsoon periods. However, the simulations showed some sensitivity to cloud microphysics options considered. Availability of measured convective updrafts will be very useful to validate the simulated updrafts and also to use as a basis for improving cloud microphysics in the models.
The convective updrafts and downdrafts associated with this thunderstorm derived from the MST radar data are shown in Fig. 5. The time is given in Indian Standard Time (IST), which is $05: 30 \mathrm{~h}$ ahead of the Universal Coordinated Time (UTC). The MST radar observations were taken only from 15:00 IST. Updrafts are observed at Gadanki 

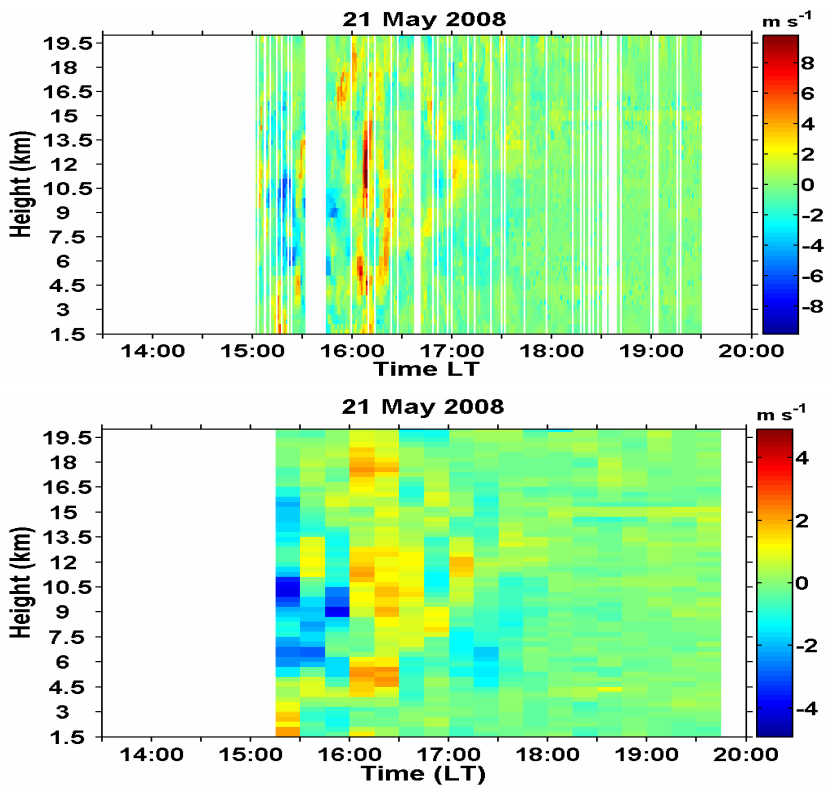

Fig. 5. Vertical velocity $\left(\mathrm{m} \mathrm{s}^{-1}\right)$ derived from the MST radar data on 21 May 2008. The top panel shows wind speed averaged over a minute and the bottom panel shows the same averaged over $15 \mathrm{~min}$.

almost for two hours, from 15:00 to 17:00 IST. The observed feature suggests two updraft cores, one just after 15:00 h (09:30 UTC) and another after an hour (16:00 h/10:30 UTC). The second core was much stronger with updrafts exceeding even $8 \mathrm{~m} \mathrm{~s}^{-1}$. Just before the passage of the second core, downdrafts are observed between 5 and $10 \mathrm{~km}$. The first core was mostly confined only up to $4.5 \mathrm{~km}$ while the second core extended more than $18 \mathrm{~km}$. An important feature is the large downdrafts observed between 15:00 and 16:00 h, just before the passage of the second core. Downdraft with lesser intensity also was observed during the passage of the second core at Gadanki, below about $7 \mathrm{~km}$.

\subsection{Simulations of updraft and downdraft profiles}

The model simulated updrafts and downdrafts associated with the thunderstorm at Gadanki are shown in Fig. 6 for the four different MP schemes. A key aspect of predicting severe thunderstorms is to represent correctly the initiation of convection. All the MP schemes simulated the initiation of updraft/downdraft cores almost an hour earlier than observed. Lean et al. (2008) using the Met office unified model showed that in the case of explicit convection, the initiation of convection takes place more rapidly as the grid length is reduced. Thompson and WSM6 schemes simulate two updraft cores with the associated downdrafts. The Lin scheme showed much disorganized updraft/downdraft cores. The Morrison scheme simulates one strong updraft core around 08:30 UTC, much earlier than observed. Comparatively, downdrafts are stronger in the Thompson scheme than any other scheme.
Thompson and WSM6 schemes simulate strong downdrafts below the updraft cores. In the observed pattern (Fig. 5) also, such a feature was noticed. The simulated updrafts are however limited below around $10 \mathrm{~km}$, while the MST radar observations show large updrafts above $10 \mathrm{~km}$. Also, the strength of the simulated updraft cores is much weaker than the observed. In the Thompson scheme, updrafts are of the order of $2 \mathrm{~m} \mathrm{~s}^{-1}$ and the WSM6 and Morrison schemes simulated updrafts exceeding $3 \mathrm{~m} \mathrm{~s}^{-1}$. However, the MST radar observations showed updrafts exceeding $8 \mathrm{~m} \mathrm{~s}^{-1}$.

In Fig. 2, it is shown that the convective event propagated towards northeast and passed Gadanki around 10:00 UTC. To examine the skill of the model in simulating northward propagation of the convective event, plots showing northward movement of simulated vertical updraft cores were prepared and the results are shown in Fig. 7. All the four MP schemes showed northward propagation of the convective updraft cores. However, the Thompson scheme simulated more downdrafts behind the updraft cores. In the Lin scheme, downdrafts are hardly simulated. The model simulates the propagation of about $30 \mathrm{~km}$ by the convective event in $2 \mathrm{~h}$.

\subsection{Simulation of rainfall and surface wind}

Figure 8 shows simulated rainfall accumulated for $24 \mathrm{~h}$ ending 00:00 UTC of 22 May 2008. The observed rainfall pattern is shown in Fig. 4a, which showed rainfall of the order of $30-35 \mathrm{~mm}$. There are large variations in the simulated rainfall associated with the thunderstorm. All the MP schemes simulate appreciable rainfall above $12.5^{\circ} \mathrm{N}$ and between $77.5^{\circ}$ and $79.0^{\circ} \mathrm{E}$. There is little rain simulated east of $79^{\circ} \mathrm{E}$. However, the magnitudes of simulated rainfall varied from one MP scheme to another. Thompson scheme simulates rainfall amounts of the order of $30 \mathrm{~mm}$, which is reasonably in agreement with the observations. However, other schemes simulate rainfall amounts exceeding $50 \mathrm{~mm}$ over a larger area. In spite of weaker updraft and downdraft cores, Lin scheme simulated higher amounts of rainfall. However, over Gadanki, the MP schemes simulated rainfall not more than $1.5 \mathrm{~mm}$, while the observed rainfall was $21 \mathrm{~mm}$. These large differences in simulated rainfall could be due to the differences in simulated hydrometeors simulated in the model. This aspect will be further discussed in Sect. 3.4.

Figure 9 shows the surface wind features over Gadanki simulated by the four MP schemes. Associated with the passage of the thunderstorm, surface wind changed from northwesterly to southeasterly and the wind gusted to $7.5 \mathrm{~m} \mathrm{~s}^{-1}$ around 10:00 UTC just before the arrival of rain. Interestingly, all the four MP schemes simulated the wind variations reasonably well, especially the wind direction. Comparatively, the Thompson scheme simulated stronger wind gust (about $10 \mathrm{~m} \mathrm{~s}^{-1}$ ) compared to other schemes. These differences in the simulated wind speed may be associated with the differences in the strength of downdrafts simulated in the 

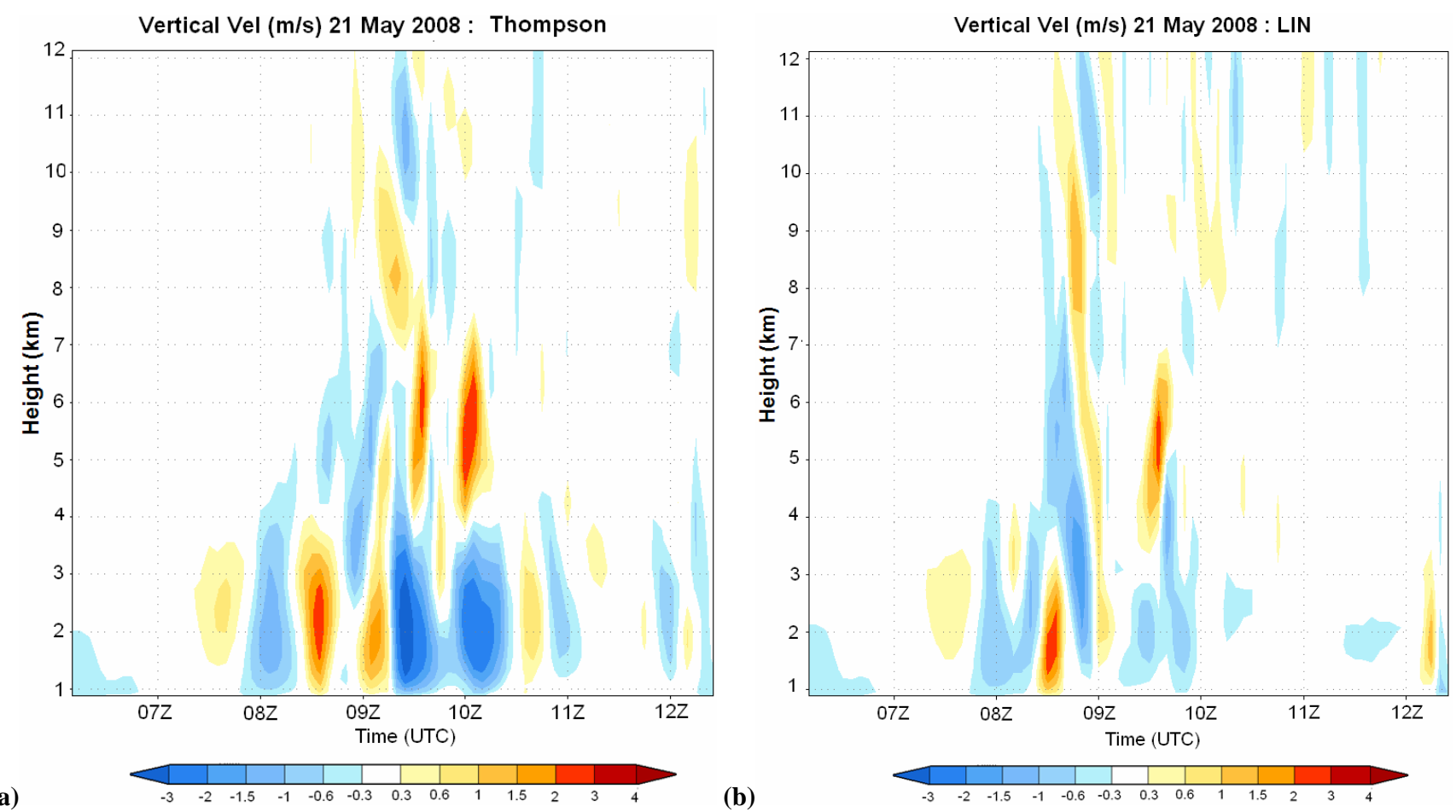

(a)
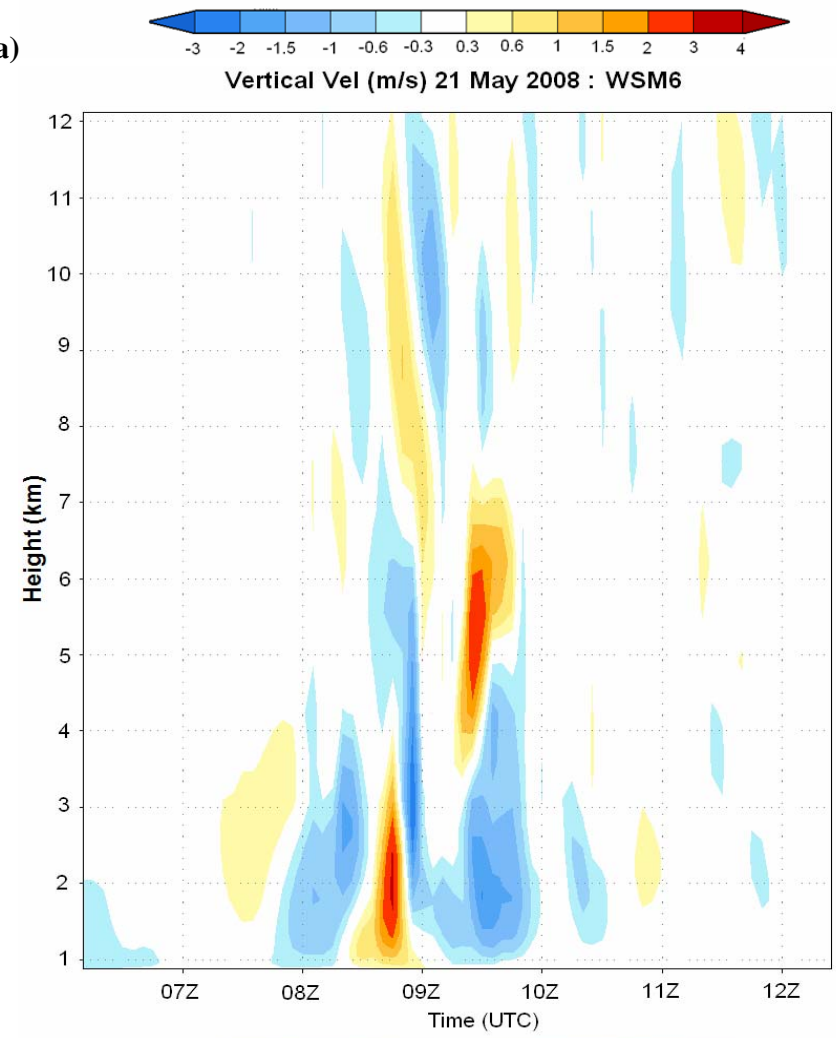

(c)

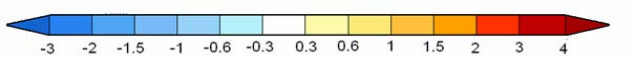

(b)

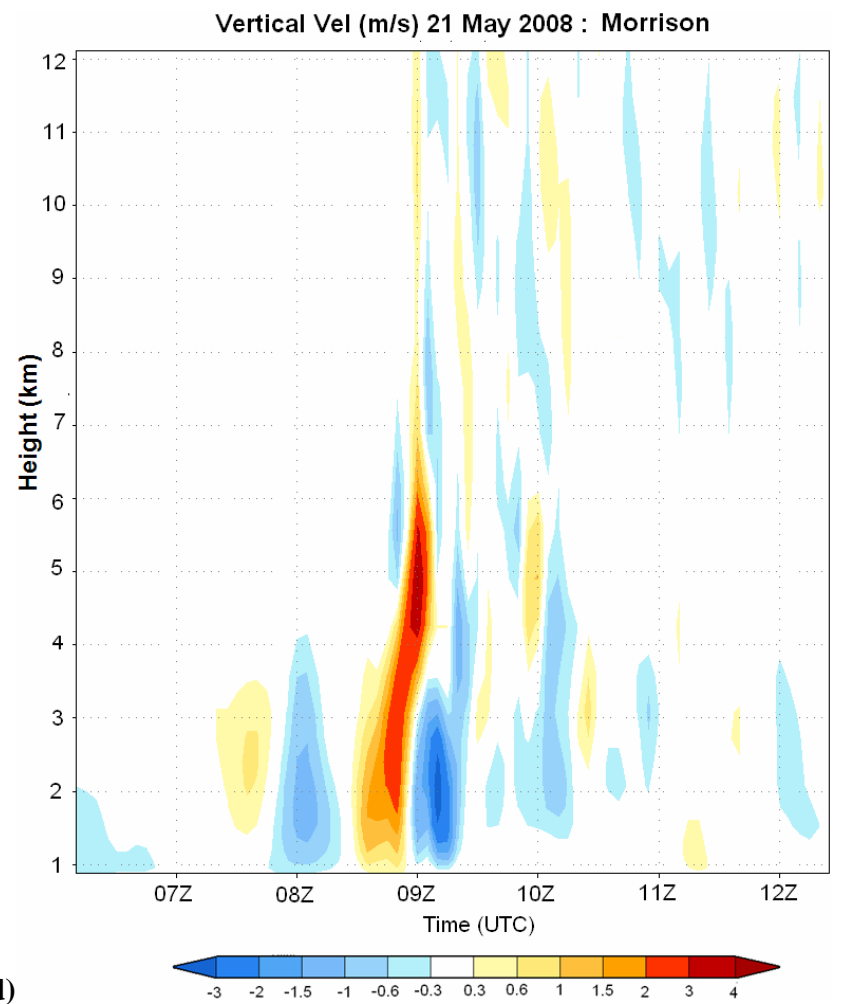

Fig. 6. Model simulated (inner most domain) vertical velocity $\left(\mathrm{m} \mathrm{s}^{-1}\right.$ ) over Gadanki with (a) Thompson, (b) Lin, (c) WSM6, and (d) Morrison. Positive (negative) values refer to updraft (downdraft). 

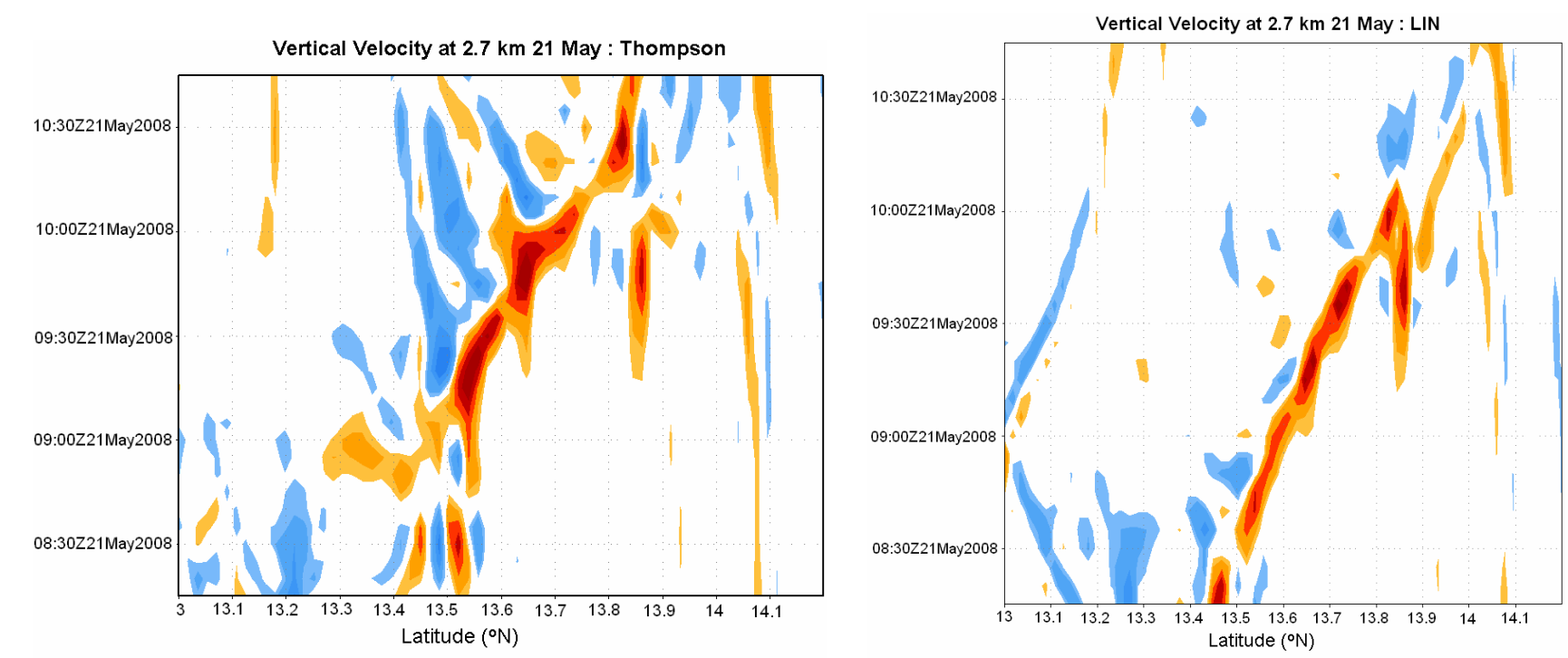

(a)

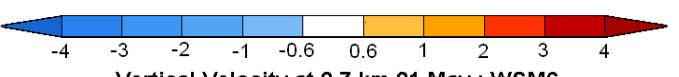

(b)
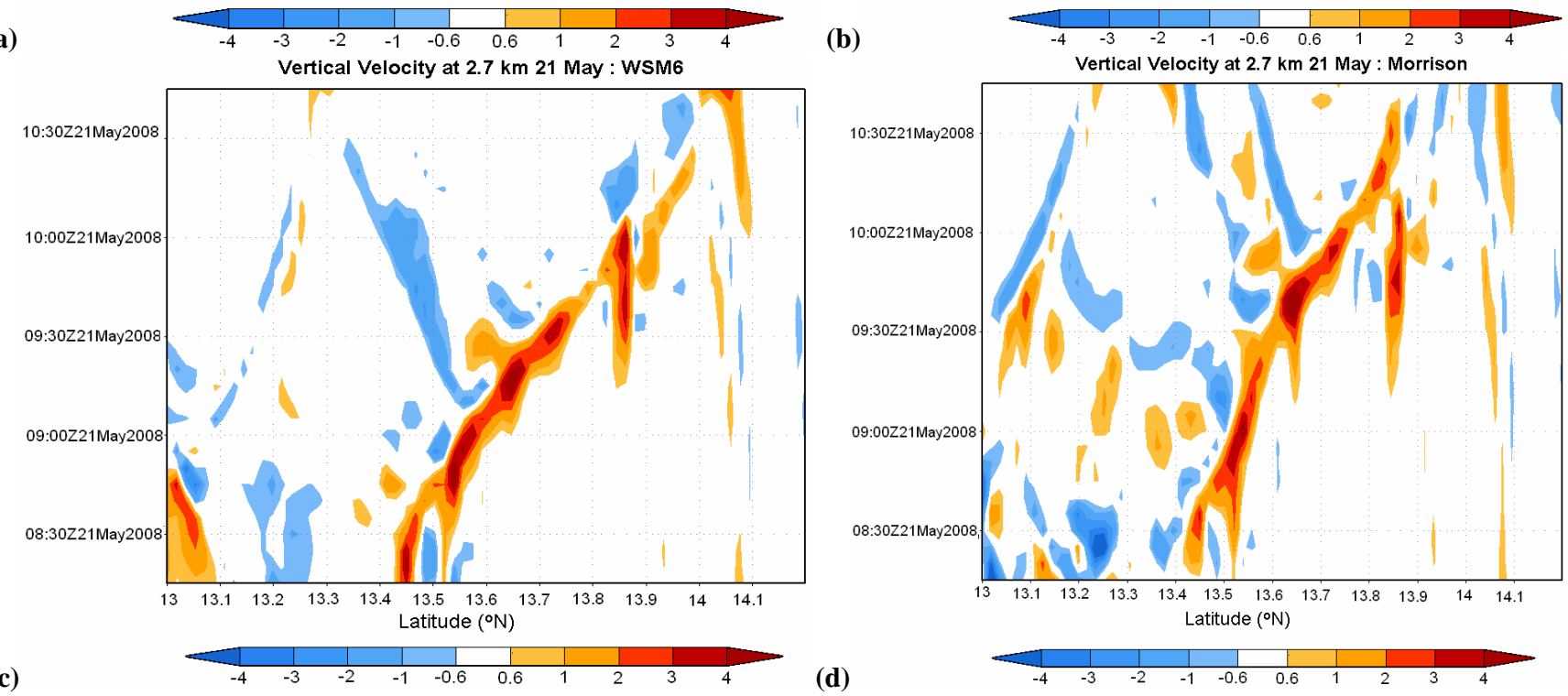

Fig. 7. Latitude-Time plot showing northward propagation of vertical velocity $\left(\mathrm{m} \mathrm{s}^{-1}\right)$ at $2.7 \mathrm{~km}$ simulated by the model with four different MP schemes. (a) Thompson, (b) Lin, (c) WSM6, and (d) Morrison.

model (Fig. 6), which in turn depends upon the parameterization of evaporation of precipitation.

\subsection{Simulation of vertical profile of reflectivity and hydrometeors}

The analysis of model simulations showed that during the passage of the thunderstorm, atmospheric water vapour was pumped up to higher levels by convection, especially in the 4-7 km layer (Fig. 10). In the same diagram, drying up the lower atmospheric layer due to downdrafts associated with the thunderstorm is also clearly seen. Therefore large increase in hydrometeors and thus reflectivity can be expected to occur in the mid-troposphere. Figure 11 shows the tempo- ral evolution of simulated reflectivity profiles by the four MP schemes. All the four schemes simulated two vertical cores of maximum reflectivity over Gadanki, which was similar to observed profiles shown in Fig. 4b. The two core structure also was seen in the simulated vertical velocity profiles (Fig. 6). In the Lin scheme, reflectivity values are smaller compared to other schemes. In the Morrison scheme, the reflectivity profile values in the first updraft core exceeded $40 \mathrm{dbz}$, the second core was much weaker. The Thompson scheme also simulates reflectivity exceeding $40 \mathrm{dbz}$. One important difference between the simulated and observed profiles is levels of maximum reflectivity. While the observed profile from the DWR shows maximum reflectivity extending 
Rainfall (mm) $24 \mathrm{hrs}$ 21-22 May: Thompson

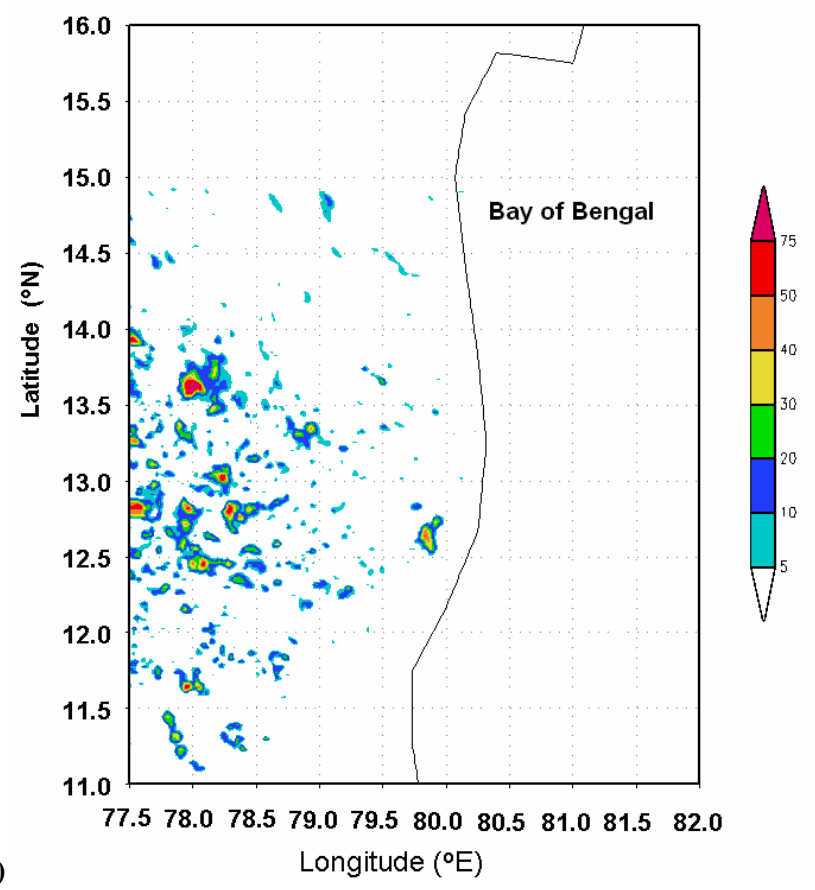

(a)

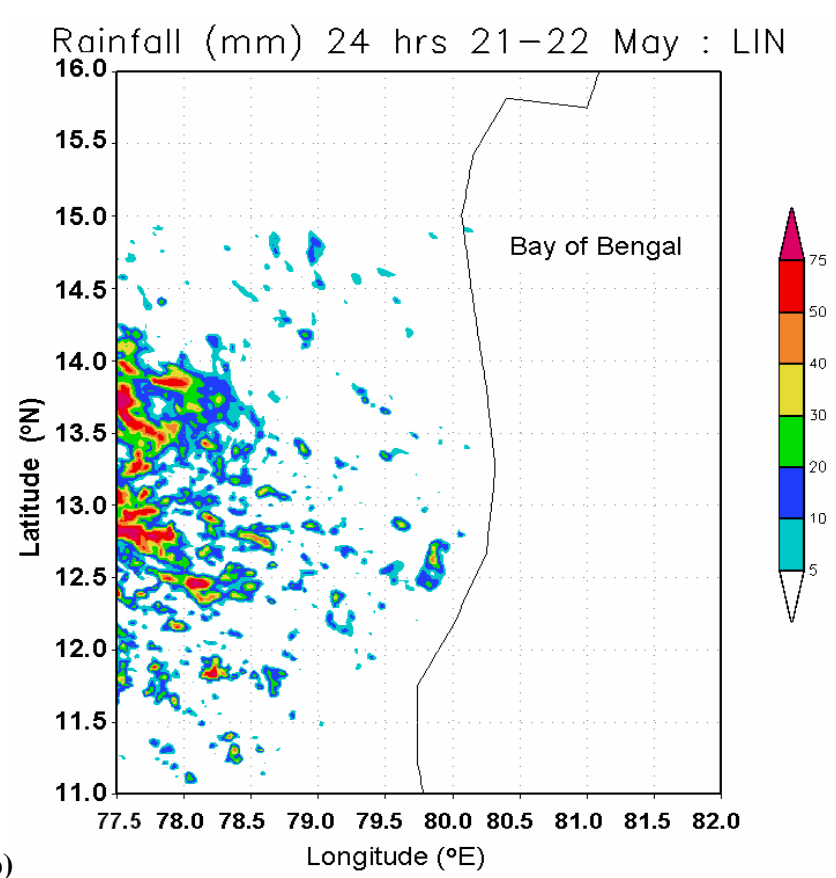

Rainfall (mm) 24 hrs 21-22 May: WSM6

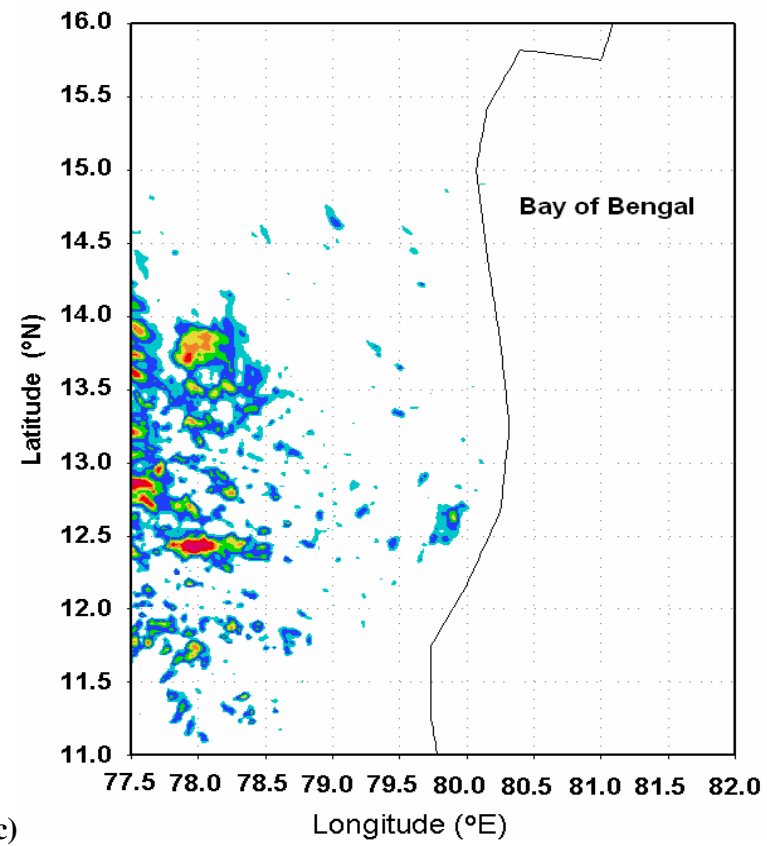

(b)

Rainfall (mm) 24 hours 21-22 May : Morrison

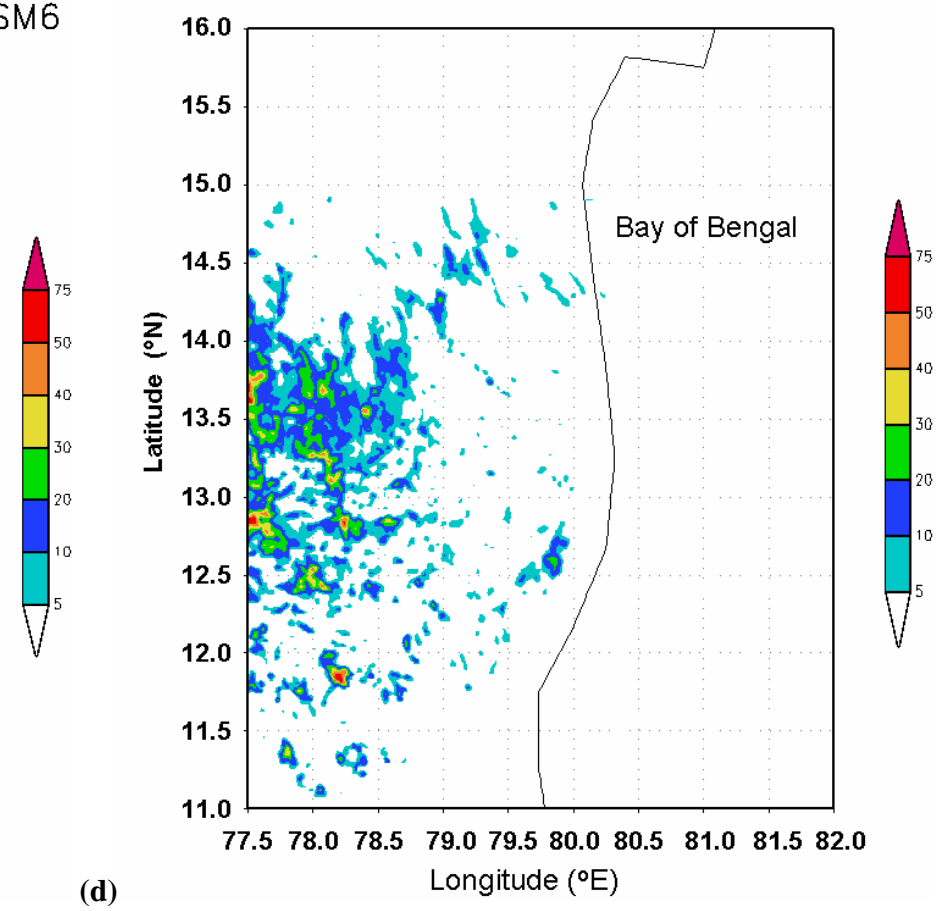

Fig. 8. Accumulated $24 \mathrm{~h}$ rainfall at 00:00 UTC on 22 May 2008 simulated by the model with four different MP schemes (a) Thompson, (b) Lin, (c) WSM6, and (d) Morrison.

right from $1 \mathrm{~km}$ to $5 \mathrm{~km}$, the simulated profiles showed maximum reflectivity in the layer between $3-6 \mathrm{~km}$. Zipser and Lutz (1994) used radar reflectivity data from central US,
Australia and oceanic monsoon regimes. They found that in sharp contrast, tropical continental vertical profiles exhibit maximum reflectivity somewhat above the surface and have a 

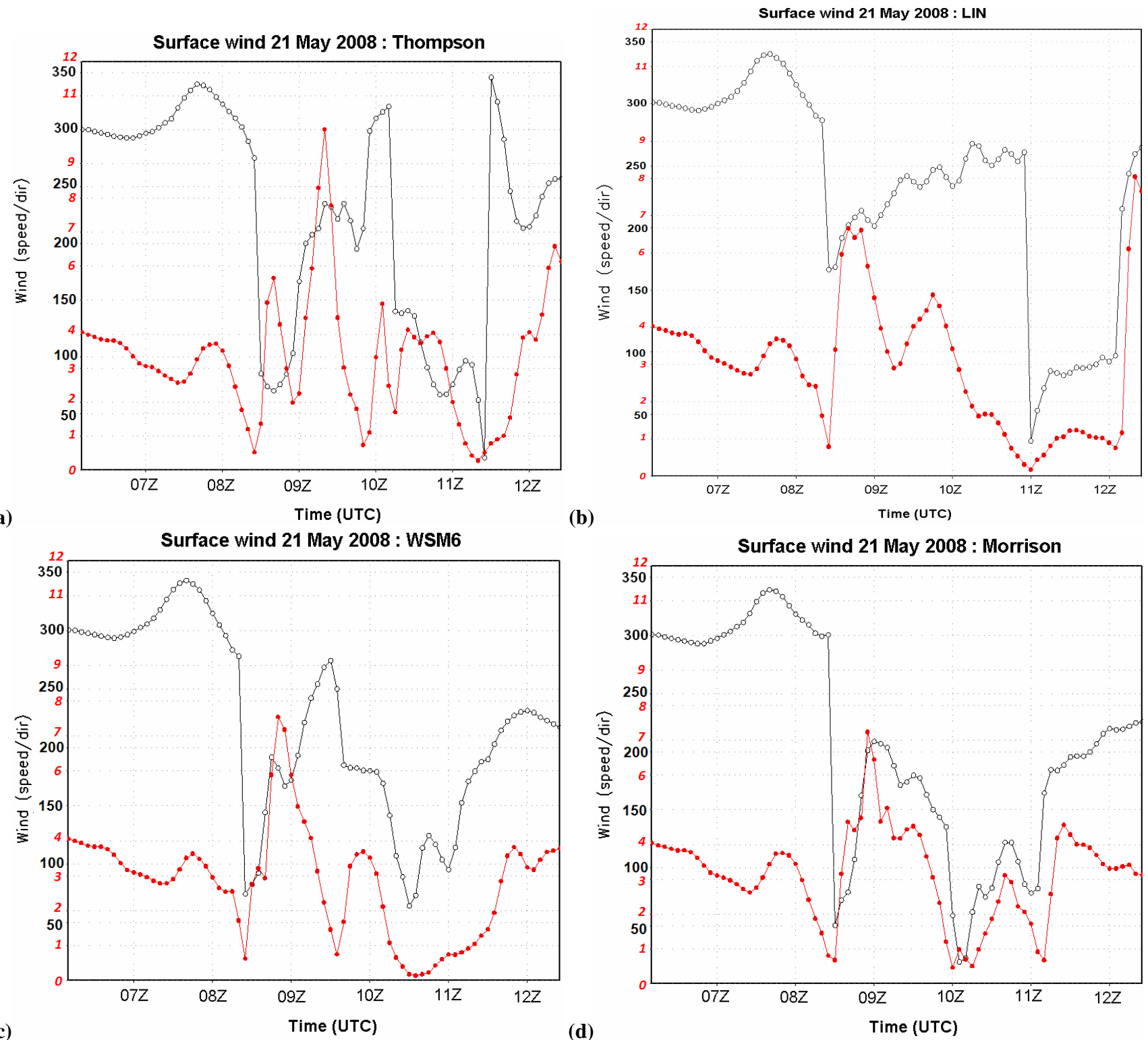

(c)

Fig. 9. Surface wind direction (black) and speed $\left(\mathrm{m} \mathrm{s}^{-1}\right)$ (red) at Gadanki simulated by the model with four different MP Schemes (a) Thompson, (b) Lin, (c) WSM6, and (d) Morrison.

gradual decrease in reflectivity with height above the freezing level. There is no study in India, analyzing vertical profiles of radar reflectivity of many cases of convective storms. The peak in the simulated reflectivity near the $5 \mathrm{~km}$ level could be due to the presence of maximum hydrometeors at this level. This aspect is discussed below.

Figure 12 shows the area averaged and time averaged vertical profiles of hydrometeors simulated by the four MP schemes. There are large differences in the vertical profile of hydrometeors. The largest differences are noticed in the rain water and graupel simulations. The Thompson scheme simulates less cloud and rain water compared to the Lin and
WSM6 schemes. Amount of rain water in the Lin scheme is much larger, explaining large amount of accumulated rainfall simulated over the area (Fig. 8). All the four MP schemes simulate graupel maximum around $6 \mathrm{~km}$. While the Thompson scheme simulates moderate amount of graupel, other three schemes simulate more than twice amount of graupel. While the Thompson and Lin schemes simulate practically no cloud ice, other two schemes simulate small amounts of cloud ice. Unfortunately, we do not have any hydrometeor data for validating these simulations of hydrometeor profiles. 


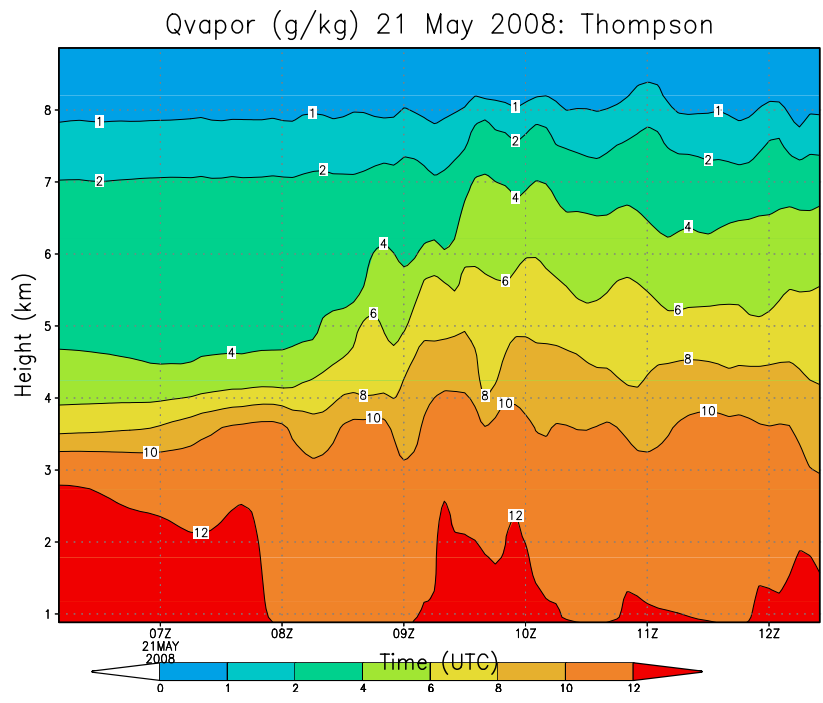

Fig. 10. Temporal evolution of atmospheric water vapour $\left(\mathrm{g} \mathrm{Kg}^{-1}\right)$ over Gadanki associated with the thunderstorm on 21 May. The simulations are with the Thompson microphysical scheme.

\section{Conclusions}

In the present study, we made cloud-resolving simulations of a severe thunderstorm observed over Gadanki (India) on 21 May 2008, using a high resolution WRF model with $2 \mathrm{~km}$ grid spacing. The present study was taken up to examine whether the WRF model is able to simulate the main features of the thunderstorm and to examine its sensitivity to different microphysical schemes. To examine the sensitivity of the simulations to different cloud microphysics, four different microphysical schemes (Thompson, WSM6, Lin and Morrison) were considered. The model was able to simulate many features of the thunderstorm, but with some differences. First of all, convection was initiated in the model, almost an hour earlier than observed. However, all the simulations correctly suggested passage of two convective cores over Gadanki, as observed by the MST and Doppler Weather radars. The study showed large variations among the four MP schemes. Significant variations are observed in the simulations of updraft/downdraft cores, surface rainfall and hydrometeor profiles. Model simulated updraft and downdrafts were weaker than observed and also constrained below about $10 \mathrm{~km}$. Among the four schemes considered, the Thompson scheme simulations were closer to observations. In spite of more sophistication, the Morrison scheme, which is a double moment scheme with 10 variables did not perform better.

The present study has some caveats. The present results are derived from the simulation of a single convective event. We propose to do simulations for more number of convective storms observed over Gadanki with cloud resolving resolutions (of the order of $2 \mathrm{~km}$ ) to generalize the results obtained in this study, even though the computational cost is large.
Similarly, instead of three nested domains, one single cloudresolving domain may be preferred in order to avoid influence of convection parameterization in the outer domains. Nevertheless, the present study has brought out the problems associated with the simulation of features associated with thunderstorms and its sensitivity to different microphysical schemes. It is important to understand the physical causes why the MP schemes had difficulty in simulating correctly the strength and vertical extend of convective updrafts and downdrafts associated with the thunderstorm. It is interesting to note that the Morrison scheme is a double moment scheme, in which the number concentration of hydrometeors is treated explicitly in addition to mixing ratios. There are large differences in the simulations of graupel. We have not understood whether inclusion of graupel is crucial in simulating the characteristics of convective clouds. The Thompson scheme, which did reasonably well in simulating the updrafts, is in fact designed to improve the mid-latitude winter precipitation. Modeling of the ice phase remains particularly uncertain (Morrison et al., 2009) due to several assumptions inherent in the representation of the ice particle size spectrum and bulk density. Another important aspect is lack of microphysical data representing tropical conditions, which can be used to parameterize the cloud microphysics. All these points highlight the importance of field experiments and measurements, which may help reduce uncertainty in these parameters that vary widely depending upon local conditions. The model simulations also may be sensitive to the $\mathrm{BMJ}$ cumulus parameterization scheme used in the outer domains. More studies are required to examine the sensitivity of cumulus schemes used in the outer domains on the simulation of observed features of the thunderstorm event.

Another area of uncertainty is the impact of aerosol chemistry and composition on heterogenous ice and droplet nucleation. The presence of slightly soluble species can affect droplet activation. A recent study (Khain et al., 2005) addressed this important issue, in which the mechanisms through which atmospheric aerosols affect cloud microphysics, dynamics and precipitation are investigated. They have found a significance effect of aerosols on cloud microphysics and dynamics. Clouds arising under continental aerosol conditions produce a stronger downdrafts and stronger convergence in the boundary layer. Being triggered by larger dynamical forcing, secondary clouds arising in microphysically continental air are stronger and can form a squall line. In the maritime aerosol cases, cloud developing under the same thermodynamic conditions do not produce strong downdrafts and do not lead to squall line formation. Using Tropical Rainfall Measuring Mission (TRMM) data, Petersen and Rutledge (2001) indicated a distinct preference for extreme intense convective events to be located over land. The simulations by Khain et al. (2005) showed that aerosols, which decrease the precipitation efficiency of most single clouds, can contribute to the formation of very intensive convective clouds and thunderstorms accompanied 

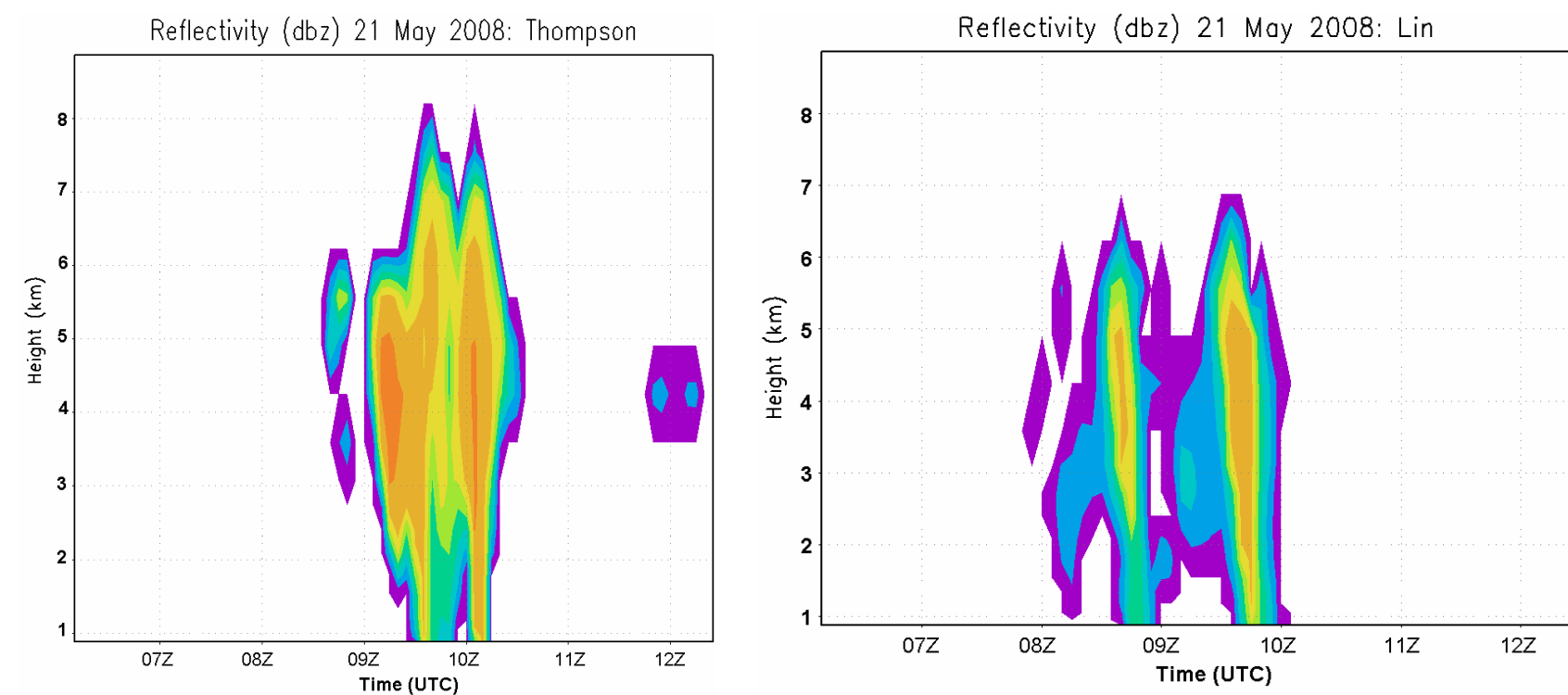

(a)
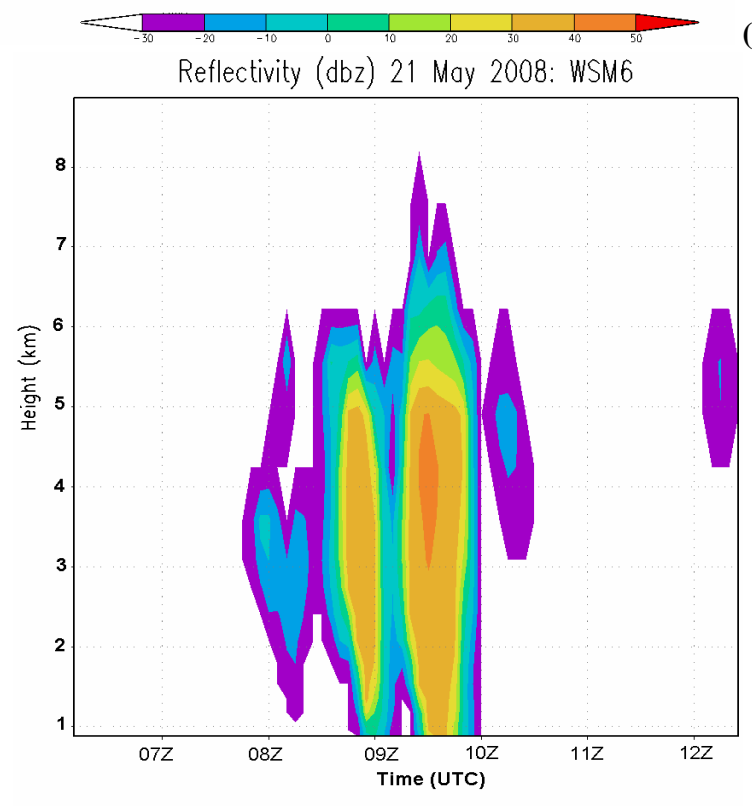

(c)

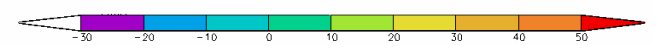

(b)
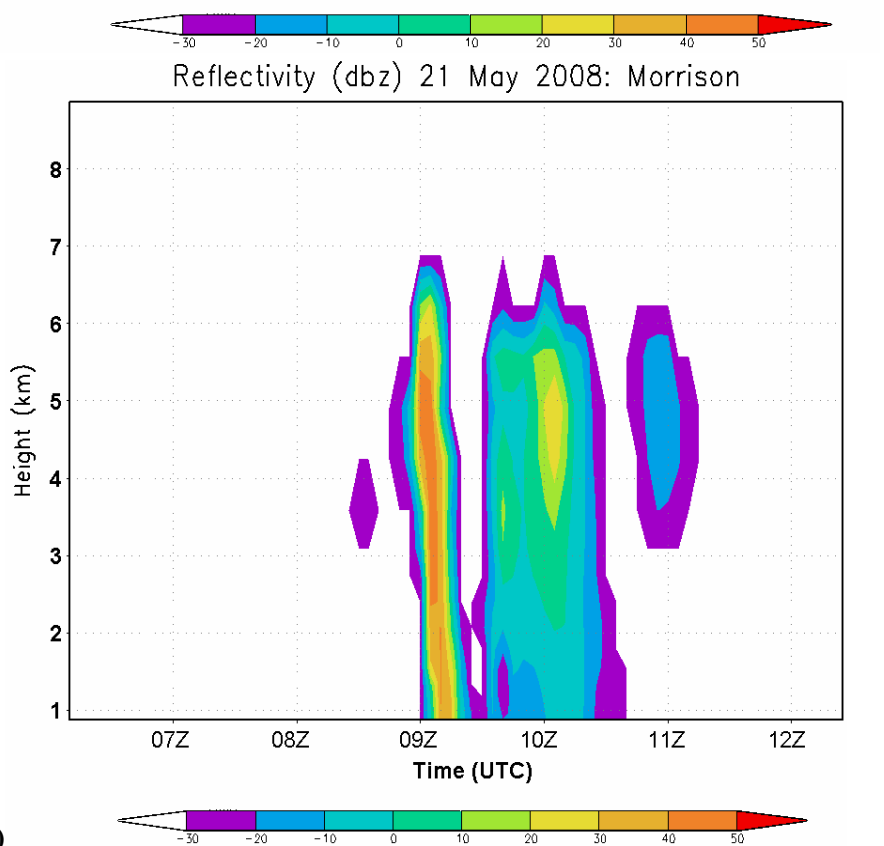

Fig. 11. Vertical profile of reflectivity (dbz) at Gadanki simulated by the model with four different MP Schemes (a) Thompson, (b) Lin, (c) WSM6, and (d) Morrison.

by very high precipitation rates. Another uncertainty in simulating the convection and its triggering mechanism is land use heterogeneity. Pielke Sr. (2001) demonstrated that land use changes can affect the deep cumulonimbus convection. The spatial structure of the surface heating, as influenced by landscape patterning, produces focused regions for deep cumulonimbus convection. In the tropics, deep cumulus convection had apparently been significantly altered as a result of landscape changes. Changes in land surface properties are shown to influence the heat and moisture fluxes within the planetary boundary layer and CAPE. The model simulations also are sensitive to the initial conditions. To examine this aspect, we repeated the model runs with 12:00 UTC of 20 May data as initial conditions and the Thompson scheme as the microphysics scheme. We found that the model was not able to simulate the observed features of the thunderstorm in detail (results not shown). As the results are dependent on initial conditions, in simulations with different initial conditions, different schemes may become closer to observations. Therefore, the present results should be used in the perspective that the model outcome is sensitive to the choice of cloud microphysics. 


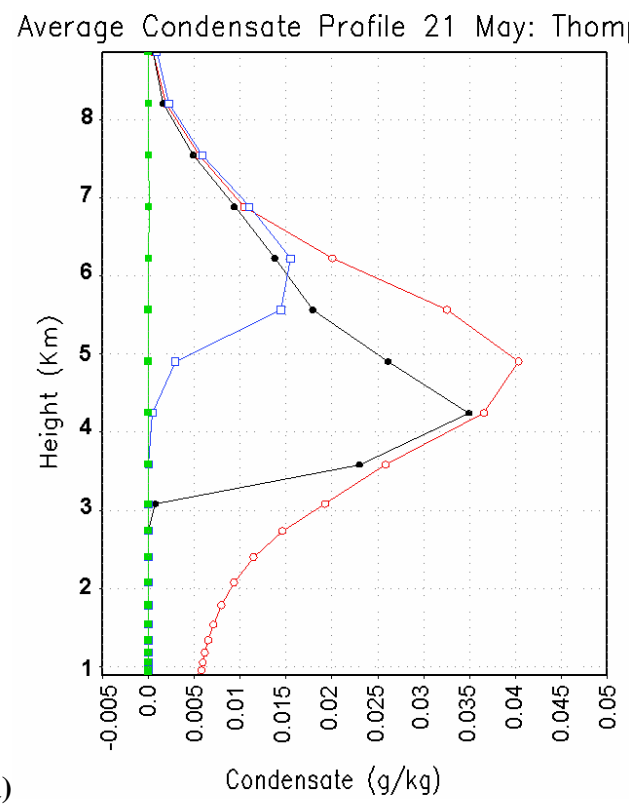

(a) Condensate $(\mathrm{g} / \mathrm{kg})$
Average Condensate Profile 21 May: WSM6
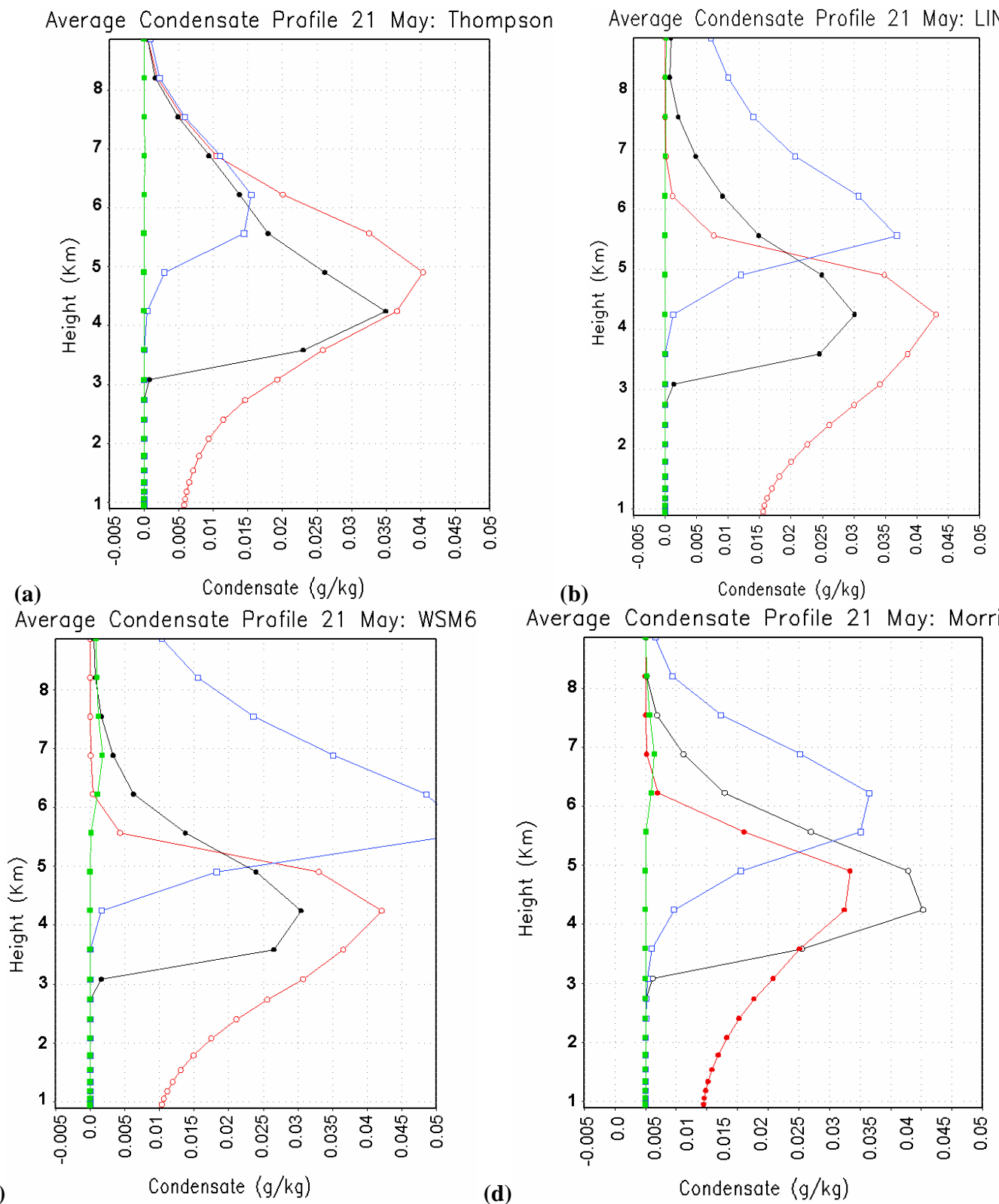

Average Condensate Profile 21 May: Morrison

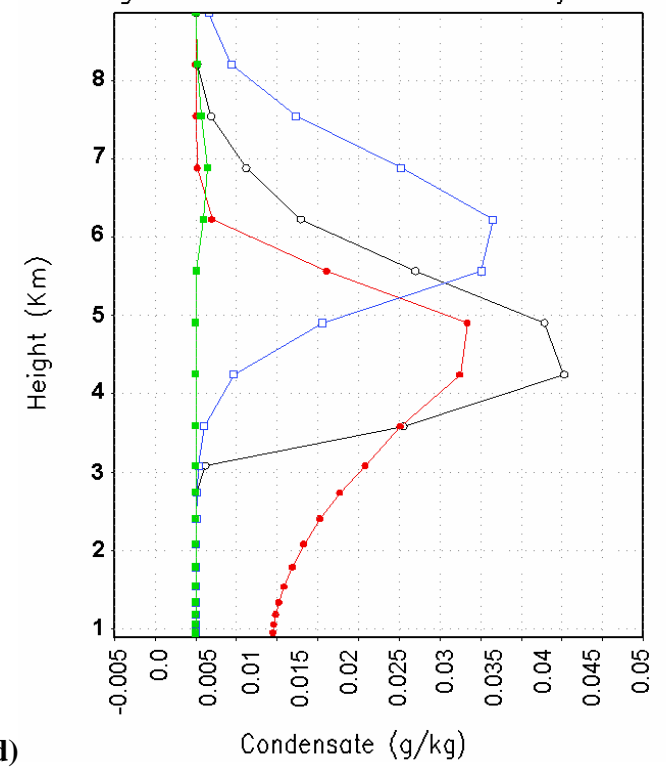

Fig. 12. Vertical profiles of cloud condensate (Cloud water (red), rain water (black), cloud Graupel (Blue) and Cloud Ice (Green)) in $\mathrm{g} \mathrm{Kg}^{-1}$ simulated by the model with four different MP schemes (a) Thompson, (b) Lin, (c) WSM6, and (d) Morrison.

All the above conclusions suggest a comprehensive observational campaign to understand and better parameterize the atmospheric convection and cloud microphysics through measurements of aerosol, cloud properties, thermodynamic parameters and land use heterogeneity. This will require multi observational platforms from a simple rain gauge to complex polarimetric radars, aircrafts and satellites.

Acknowledgements. We are thankful to the Chairman, ISRO, T. G. K. Murthy, A. Jayaraman and B. Manikiam for their kind encouragement and extending support to carry out this study. All the model runs were made with the super computing facility at the Computational Research Laboratory (CRL), Tata Sons, Pune, India (www.crlindia.com). We are thankful to CRL for providing the computing facility. We also thank Jyoti Bhate and Debashis Nath for their technical support. We are also thankful to two anonymous reviewers for their constructive comments and suggestions to improve the quality of the paper.

Topical Editor F. D'Andrea thanks two anonymous referees for their help in evaluating this paper. 


\section{References}

Chen, S. H. and Sun, W. Y.: A one dimensional time-dependent cloud model, J. Meteorol. Soc. Japan, 80, 99-118, 2002.

Done, J., Davis, C. A., and Weisman, M.: The next generation of NWP: Explicit forecasts of convection using the weather research and forecasting (WRF) model, Atmos. Sci. Lett., 5, 110117,2004

Dudhia, J.: Numerical study of convection observed during the winter monsoon experiment using a mesoscale two-dimensional model, J. Atmos. Sci., 46, 3077-3107, 1989.

Gilmore, M. S., Straka, S. M., and Rasmussen, E. N.: Precipitation and evolution sensitivity in simulated deep convective storms: comparisons between liquid-only and simple ice and liquid phase microphysics, Mon. Weather Rev., 132, 1897-1916, 2004.

Hong, S. Y., Dudhia, J., and Chen, S. H.: A revised approach to ice microphysical processes for the bulk parameterization of clouds and precipitation, Mon. Weather Rev., 132, 103-120, 2004.

Houze Jr., R. A.: Mesoscale Convective Systems, Rev. Geophys., 42, 1-43, doi:10.1029/2004RG000150, 2004.

Houze Jr., R. A.: Cloud Dynamics, 573 pp, Academic, San Diego, California, 1993.

Jagannadha Rao, V. V. M., Narayana Rao, D., Ratnam, M. V., Mohan, K., and Vijaya Bhaskara Rao, S.: Mean vertical velocities measured by Indian MST radar and comparison with indirectly computed values, J. Appl. Meteorol., 42, 541-552, 2003.

Kain, J. S., Weiss, S. J., Levit, J. J., Baldwin, M. E., and Bright, D. R.: Examination of convection-allowing configurations of the WRF model for the prediction of severe convective weather: The SPC/NSSL spring program 2004, Wea. Forecasting, 21, 167$181,2006$.

Kain, J. S., Weiss, S. J., Bright, D. R., et al.: Some practical considerations regarding horizontal resolution in the first generation of operational convection-allowing NWP, Wea. Forecasting, 23, 931-952, 2008.

Khain, A., Rosenfeld, D., and Pokrovsky, A.: Aerosol impact on the dynamics and microphysics of deep convective clouds, Q. J. Roy. Meteorol. Soc., 131, 2639-2663, 2005.

Lean, H. W., Clark, P. A., Dixon, M., Roberts, N. M., Fitch, A., Forbes, R., and Halliwell, C.: Characteristics of High-resolution versions of the Met Office Unified Model for forecasting convection over the United Kingdom., Mon. Weather Rev., 136, 34083424, 2008.

Lin, Y. L., Farley, R., and Orville, H. D.: Bulk parameterization of the snow field in a cloud model, J. Climate Appl. Meteor., 22, 1065-1092, 1983.

Litta, A. J. and Mohanty, U. C.: Simulation of a severe thunderstorm event during the field experiment of STORM programme 2006, using WRF-NMM model, Current Sci., 95, 204-214, 2008.

Liu, C. and Moncrieff, M. W.: Sensitivity of cloud-resolving simulations of warm-season convection to cloud microphysics parameterizations, Mon. Weather Rev., 135, 2854-2868, 2007.

Liu, C. H., Moncrieff, M. W., Tuttle, J. D., and Carbone, R. E.: Explicit and parameterized episodes of warm-season precipitation over the continental United States, Adv. Atmos. Sci., 23, 91-105, 2006.

McCumber, M., Tao, W. K., Simspon, J., Penc, R., and Soong, S. T.: Comparison of ice-phase microphysical parameterization schemes using numerical simulations of tropical convection, J.
Appl. Meteorol., 30, 985-1004, 1991.

Mlawer, E. J., Taubman, S. J., Brown, P. D., Iacano, M. J., and Clough, S. A.: Radiative transfer for inhomogeneous atmosphere: RRTM, a validate correlated-k model for the longwave, J. Geophys. Res, 102, 16663-16682, 1997.

Moncrieff, M. W. and Liu, C. H.: Representing convective organization in prediction models by a hybrid strategy, J. Atmos. Sci., 63, 3404-3420, 2006.

Mukhopadhyay, P., Sanjay, J., Cotton, W. R., and Singh, S. S.: Impact of surface meteorological observations on RAMS forecast of monsoon weather systems over Indian region, Meteorol. Atmos. Phys., 90, 77-108, 2005.

Morrison, H., Thompson, G., and Tatarskii, V.: Impact of cloud microphysics on the development of trailing stratiform precipitation in a simulated squall line: Comparison of one and two-moment schemes, Mon. Weather Rev., 137, 991-1006, 2009.

Petersen, W. A. and Rutledge, S. A.: Regional variability in tropical convection: Observations from TRMM, J. Climate, 14, 35663586, 2001.

Pielke Sr., R. A.: Influence of the Spatial Distribution of Vegetation and Soils on the Prediction of Cumulus Convective Rainfall, Rev. Geophys., 39(2), 151-177, 2001.

Rajeevan, M. and Jyoti Bhate: A high resolution daily gridded rainfall dataset (1971-2005) for mesoscale meteorological studies, Current Sci., 96, 558-562, 2009.

Rao, P. B., Jain, A. R., Kishore, P., Balamuralidhar, P., Damle, S. H., and Viswanathan, G.: Indian MST Radar I. System description and sample vector win measurements in ST mode, Radio Sci., 30, 1125-1138, 1995.

Rao, P. V., Vinay Kumar, P., Ajay Kumar, M. C., and Dutta, G.: Long-term mean vertical velocity measured by MST radar at

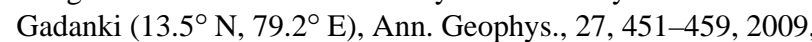
http://www.ann-geophys.net/27/451/2009/.

Reisner, J., Rasmussen, R. J., and Bruintjes, R. T.: Explicit forecasting of super cooled liquid water in winter storms using the MM5 Mesoscale model, Q. J. Roy. Meteorol. Soc., 124B, 1971-1107, 1998.

Rutledge, S. A. and Hobbs, P. V.: The mesoscale and microscale structure and organization of clouds and precipitation in midlatitude cyclones XII: A diagnostic modeling study of precipitation development in narrow clod-frontal rainbands, J. Atmos. Sci., 41, 2949-2972, 1984.

Speer, M. S. and Leslie, L. M.: The prediction of two cases of severe convection: implications for forecast guidance, Meteor. Atmos. Phys., 80, 1-4, 2002.

Thompson, G., Rasmussen, R. M., and Manning, K.: Explicit forecasts of winter precipitation using an improve bulk microphysics scheme. Part-I: Description and sensitivity analysis, Mon. Weather Rev., 132, 519-542, 2004.

Trier, S. B., Davis, C. A., Ahijevych, D. A., Weisman, M. L., and Bryan, G. H.: Mechanisms supporting long-lived episodes of propagating nocturnal convection within a 7-day WRF model simulation, J. Atmos. Sci., 63, 2437-2461, 2006.

Uma, K. N. and Narayana Rao, T.: Characteristics of vertical velocity cores in different convective systems observed over Gadanki, India., Mon. Weather Rev., 137, 953-977, 2009.

Wilson, J. M., Crook, N. A., Mueller, C. K., Sun, J., and Dixon, M.: Nowcasting thunderstorms: A status report, B. Am. Meteorol. Soc., 79, 2079-2099, 1998. 
Weisman, M. L., Skamarock, W. C., and Kemp, J. B.: The resolution dependence of explicitly modeled convective systems, Mon. Weather Rev., 125, 527-548, 1997.

Wu, J., Del Genio, A. D., Yao, M. S., and Wolf, A. B.: WRF and GISS SCM simulations of convective updraft properties during TWP-ICE, J. Geophys. Res., 114, D04206, doi:10.1029.2208JD010851, 2009.

$\mathrm{Xu}, \mathrm{K} . \mathrm{M}$. and Randall, D. A.: Updraft and downdraft statistics of simulated tropical and midlatitude cumulus convection, J. Atmos. Sci., 58, 1630-1649, 2001.
Zipser, E. J., Cecil, D. J., Liu, C., Nesbitt, S. W., and Korty, D. P.: Where are the most intense thunderstorms on Earth?, B. Am. Meteorol. Soc., 87, 1057-1071, 2006.

Zipser, E. J. and Lutz, K. R.: The vertical profile of radar reflectivity of convective cells: A strong indicator of storm intensity and Lightning probability?, Mon. Weather Rev., 122, 1751-1759, 1994. 